WHEN STUDYING AND NUDGING DON'T GO AS PLANNED:

UNSUCCESSFUL ATTEMPTS TO HELP TRADITIONAL AND ONLINE COLLEGE STUDENTS

Philip Oreopoulos

Richard W. Patterson

Uros Petronijevic

Nolan G. Pope

WORKING PAPER 25036 
NBER WORKING PAPER SERIES

\title{
WHEN STUDYING AND NUDGING DON'T GO AS PLANNED: UNSUCCESSFUL ATTEMPTS TO HELP TRADITIONAL AND ONLINE COLLEGE STUDENTS
}

\author{
Philip Oreopoulos \\ Richard W. Patterson \\ Uros Petronijevic \\ Nolan G. Pope \\ Working Paper 25036 \\ http://www.nber.org/papers/w25036
NATIONAL BUREAU OF ECONOMIC RESEARCH
1050 Massachusetts Avenue \\ Cambridge, MA 02138 \\ September 2018, Revised April 2019
}

\begin{abstract}
Previously circulated as "Lack of Study Time is the Problem, but What is the Solution? Unsuccessful Attempts to Help Traditional and Online College Students." At the University of Toronto, we are indebted to the first-year economics instructors for their willingness to incorporate an experiment into their courses for a fourth consecutive year. We especially thank James Lahey, our web developer, for his tireless commitment to designing and perfecting the experiment's website, as well as for his help with organizing and extracting the experimental data. Spencer Dean, Chelsea Kowalski, Catherine Tessier, Chester Madrazo, Ophelia Au, and Erica Rzepecki showed great enthusiasm and professionalism in their role as coaches. At WGU, we thank Jason Levin, Chelsea Barnett, and Narendra Pandya for their help designing, programming, and executing this study. Thanks also to seminar participants at the University of Michigan, Michigan State University, UC San Diego, Notre Dame University, the Institute of Behavior \& Inequality, MDRC, the Association for Public Policy Analysis and Management (APPAM) 2017 annual research conference, the Society of Labor Economists' 2018 annual meetings, and the College Board. All remaining errors are our own. The experiments in this paper were both registered with the AEA RCT Registry. The RCT IDs are AEARCTR-0000972 and AEARCTR-0000810. The views expressed herein are those of the authors and do not necessarily reflect the views of the National Bureau of Economic Research.
\end{abstract}

NBER working papers are circulated for discussion and comment purposes. They have not been peer-reviewed or been subject to the review by the NBER Board of Directors that accompanies official NBER publications.

(C) 2018 by Philip Oreopoulos, Richard W. Patterson, Uros Petronijevic, and Nolan G. Pope. All rights reserved. Short sections of text, not to exceed two paragraphs, may be quoted without explicit permission provided that full credit, including $\odot$ notice, is given to the source. 
When Studying and Nudging Don't Go as Planned: Unsuccessful Attempts to Help Traditional and Online College Students

Philip Oreopoulos, Richard W. Patterson, Uros Petronijevic, and Nolan G. Pope

NBER Working Paper No. 25036

September 2018, Revised April 2019

JEL No. I2,J24

\section{ABSTRACT}

We evaluate two low-cost college support programs designed to target insufficient study time, a common occurrence among many undergraduates. We experimentally evaluate the programs across three distinct colleges, randomly assigning more than 9,000 students to construct a weekly schedule in an online planning module and to receive weekly study reminders or coach consultation via text message. Despite high participation and engagement, and treated students at two sites marginally increasing study time, we estimate precise null effects on student credit accumulation, course grades, and retention at each site for the full sample and for multiple subgroups. The results and other supplemental evidence suggest that low-touch programs that offer scheduling assistance, encouragement, and reminders for studying lack the required scope to significantly affect academic outcomes.

$\begin{array}{ll}\begin{array}{l}\text { Philip Oreopoulos } \\ \text { Department of Economics }\end{array} & \text { Uros Petronijevic } \\ \text { University of Toronto } & \text { York University } \\ \text { 150 St. George Street } & \text { Department of Economics } \\ \text { Toronto, ON M5S 3G7 } & 4700 \text { Keele Street } \\ \text { CANADA } & \text { Toronto, ON M3J 1P3 } \\ \text { and NBER } & \text { CANADA } \\ \text { philip.oreopoulos@ utoronto.ca } & \text { upetroni@yorku.ca } \\ & \\ \text { Richard W. Patterson } & \text { Nolan G. Pope } \\ \text { United States Military Academy } & \text { University of Maryland } \\ \text { B107 Lincoln Hall } & \text { 3114 Tydings Hall } \\ \text { West Point, NY 10996 } & \text { 7343 Preinkert Dr } \\ \text { richard.patterson@ } \text { usma.edu } & \text { College Park, MD 20742 } \\ & \text { pope@econ.umd.edu }\end{array}$

A randomized controlled trials registry entry is available at AEARCTR-0000972, AEARCTR-0000810 A online appendices is available at http://www.nber.org/data-appendix/w25036 


\title{
When Studying and Nudging Don't Go as Planned: Unsuccessful Attempts to Help Traditional and Online College Students
}

\author{
Philip Oreopoulos
}

Uros Petronijevic

\author{
Richard W. Patterson
}

\section{April 2019}

\begin{abstract}
We evaluate two low-cost college support programs designed to target insufficient study time, a common occurrence among many undergraduates. We experimentally evaluate the programs across three distinct colleges, randomly assigning more than 9,000 students to construct a weekly schedule in an online planning module and to receive weekly study reminders or coach consultation via text message. Despite high participation and engagement, and treated students at two sites marginally increasing study time, we estimate precise null effects on student credit accumulation, course grades, and retention at each site for the full sample and for multiple subgroups. The results and other supplemental evidence suggest that low-touch programs that offer scheduling assistance, encouragement, and reminders for studying lack the required scope to significantly affect academic outcomes.
\end{abstract}

Acknowledgements: At the University of Toronto, we are indebted to the first-year economics instructors for their willingness to incorporate an experiment into their courses for a fourth consecutive year. We especially thank James Lahey, our web developer, for his tireless commitment to designing and perfecting the experiment's website, as well as for his help with organizing and extracting the experimental data. Spencer Dean, Chelsea Kowalski, Catherine Tessier, Chester Madrazo, Ophelia Au, and Erica Rzepecki showed great enthusiasm and professionalism in their role as coaches. At WGU, we thank Jason Levin, Chelsea Barnett, and Narendra Pandya for their help designing, programming, and executing this study. Thanks also to seminar participants at the University of Michigan, Michigan State University, UC San Diego, Notre Dame University, the Institute of Behavior \& Inequality, MDRC, the Association for Public Policy Analysis and Management (APPAM) 2017 annual research conference, the Society of Labor Economists’ 2018 annual meetings, and the College Board. All remaining errors are our own. The experiments in this paper were both registered with the AEA RCT Registry. The RCT IDs are AEARCTR-0000972 and AEARCTR-0000810. Oreopoulos - University of Toronto and NBER, philip.oreopoulos@utoronto.ca; Patterson United States Military Academy, richard.patterson@usma.edu; Petronijevic - York University, upetroni@yorku.ca; Pope - University of Maryland, pope@econ.umd.edu. 


\section{Introduction}

College enrollment has steadily increased in recent decades, as policymakers, popular media, and parents all emphasize the importance of post-secondary education for labor market success. Yet approximately half of all students who enroll never complete their program and students who do complete struggle and develop limited skills along the way (Arum and Roksa 2011). Student effort is a key determinant of academic outcomes, and many students devote an alarmingly low amount of time to regular studying (Babcock and Marks 2011). Despite a clear positive association between study time and academic outcomes (Brint and Cantwell 2010; Stinebrickner and Stinebrickner 2004, 2008), underachieving students in both traditional and online colleges often manage their time poorly and study very little (Dohetry 2006; Beattie, Laliberté, Michaud-Leclerc, and Oreopoulos 2017; Beattie, Laliberté, and Oreopoulos 2018). Indeed, any initiative to improve student outcomes is likely to be far more effective when students are consistently engaged in the learning process.

In this paper, we study three types of post-secondary education institutions - a selective four-year college, a less-selective four-year college, and an online university - that differ in terms of student characteristics and how they deliver education, but share the problem of having many students who manage their time poorly. Recent studies using students from our traditional college settings (campuses at the University of Toronto) show that struggling students have a high propensity to procrastinate and study little throughout the academic year (Beattie, Laliberte, and Oreopoulos 2018). Upon initially experiencing poor performance in first semester, these students do not increase their planned study time, despite many acknowledging that the biggest challenge

to their academic success is poor time management (Beattie, Laliberte, Michaud-Leclerc, and Oreopoulos 2017). 
A lack of available time is unlikely to be the reason for low study times. Figure 1 plots the distribution of time that students have available and the distribution of time they self-report studying during a regular week in the fall semester, using information from baseline and followup surveys among students from the two colleges in our traditional college samples. ${ }^{1}$ Available study time is calculated from a baseline survey that elicits students' self-reported expectations for weekly hours of paid work, commuting time to and from campus, time spent attending lectures, and time spent sleeping. Self-reported study time during a regular week in the fall semester is gathered from a follow-up survey at the end of the semester. The two distributions are almost nonoverlapping, suggesting that few students are limited by their available time for studying. Indeed, the median student has approximately 93 hours a week available but only chooses to devote 12 hours to studying outside the classroom. Half of students in our sample self-report studying less than 12 hours a week, while the bottom quarter of students report studying less than 5 hours per week.

At the online college we study, Western Governors University (WGU), students also appear to study infrequently. Although students have easy access to material online, the average student logs into to their portal only 2.1 days per week. In addition, 90 percent of students log in less than 3.7 days per week and 18.5 percent of students log in less than 1 day per week. More generally, online education is a setting where time management issues are particularly likely to drive poor performance. Indeed, recent experimental and quasi-experimental evidence finds that students in online courses perform worse than students in traditional classroom settings (Bettinger et al., forthcoming; Figlio et al. 2013). One possible reason for these performance gaps is that the

\footnotetext{
${ }^{1}$ We describe the data used to construct this figure in greater detail in Section 4.
} 
asynchronous, unstructured nature of online courses makes students particularly prone to issues with time management and distraction.

To address issues of poor time management and low study times, we design and evaluate two programs that aim to increase study time by helping students create and follow realistic schedules. We experimentally evaluate program impacts using a sample of over 3,500 undergraduate students at the University of Toronto (UofT) and a sample of over 6,000 undergraduate students at WGU. At UofT, we implement our program at both the more-selective main campus, St. George (UTSG), and the less-selective suburban commuter campus, the University of Toronto at Mississauga (UTM). Our experimental sample includes approximately 2,000 UTSG students and 1,500 UTM students. Across all three locations, we randomly assign incoming students to treatment or control groups. Students in the treatment group are provided information to motivate the benefits of sufficient study and complete an online planning module in which they make a calendar describing their planned weekly commitments in the upcoming year, including the times during the week they plan to study. To keep these plans salient, we also encouraged students at the UofT campuses to provide their phone numbers and students at WGU to download the WGU mobile application so that we could send students reminders about their scheduled study times via text message throughout the academic year. Students in the control groups at the UofT campuses were given a personality test, while students in the control group at WGU did not receive the planning module but still completed the standard online student orientation.

Our planning interventions relate to a broader and growing literature on the application of behavioral insights to education settings (Lavecchia, Liu, and Oreopoulos 2016; Damgaard and Nielsen 2018). Recent attempts to help improve academic outcomes focus on prompting students 
to think about future goals (Clark et al. 2017; Dobronyi et al. 2017), encouraging more healthy perspectives for dealing with setbacks or anxiety (Yeager et al. 2016; Bettinger et al. 2018), and low-cost encouragement or advising (Fryer 2016; Castleman and Meyer 2016; Oreopoulos and Petronijevic 2018). We focus instead on targeting study time, treating it as a crucial necessary (but not sufficient) condition for academic success. Poorly performing students, who typically study less than 10 hours a week, are unlikely to benefit from any intervention that does not increase this variable.

Our planning interventions are designed to improve study time management through three key channels. First, by providing information about successful students’ study habits through an online module, they make students aware of how much time is usually required to perform well in their courses. Second, by requiring that students create a weekly plan that details all their commitments, the interventions help students better understand the time commitment required for all their other obligations outside of school. Third, the periodic reminders that students receive about their planned study times help keep their goals salient throughout the academic year.

Despite our time-management program being well-received and generating a high degree of student engagement, we find no impact on academic outcomes across all three experimental sites (the two campuses of UofT and WGU). Specifically, we estimate no treatment effect on credit accumulation or course grades at UTSG and UTM and no treatment effect on student credit accumulation or retention at WGU. These results hold even after investigating potentially heterogeneous treatment effects across several student subgroups. ${ }^{2}$

\footnotetext{
${ }^{2}$ The experiments at WGU and at UofT were both pre-registered with the AEA RCT Registry. The RCT IDs are AEARCTR-0000972 and AEARCTR-0000810 at WGU and UofT, respectively. Our analysis of treatments effects in the full sample and across student subgroups closely follows our pre-registered analysis plans.
} 
Considering the mechanisms behind the null effects, we show that the intervention did significantly increase self-reported study times at the University of Toronto campuses by nearly 2 hours per week. We reconcile the null effects on grades with these positive effects on study time by showing that the association between study time and course grades is relatively low. An increase in weekly study time of 10 hours (75 percent of a standard deviation) is associated with an average increase in course grades between 2.2 and 4.6 percentage points (between 17 and 35 percent of a standard deviation), a range reflecting estimates that are adjusted to account for measurement error and potential grade inflation. The relatively weak association between study hours and grades and our first-stage effect on study time at UofT together imply grade effects that may be too small for us to detect.

A lack of engagement - both during the initial online exercise and throughout the course of the semester with text message coaching - is unlikely to explain the insignificant effects of the intervention. We document that treated students engaged with the calendar exercise by setting higher study goals in their calendars than what they reported to be expecting to study during the (pre-randomization) baseline survey. Further, response rates to the weekly text-messages were quite high, with nearly 70 percent of students engaging with their coaches. Finally, supplemental evidence suggests that most students enjoyed the program and would have liked for it to continue.

Given the high levels of student engagement and satisfaction with the intervention, it is likely that a more comprehensive program is required to generate larger change in behavior and outcomes. We further use our unique survey data at the UofT campuses to demonstrate that, in addition to studying more, top-performing students differ from low-performing students on many other important dimensions: they have much higher incoming high school grades, set higher expectations for themselves, are more likely to finish what they start, manage their time well, and 
plan well into the future, and are less likely to study at the last minute and delay starting assignments. These important differences among high- and low-performing students, coupled with the very large study effort increase that is required to generate significant change in outcomes, imply that a more comprehensive and intensive intervention - designed to affect many dimensions of student behavior - is likely required to generate meaningful change in academic outcomes.

Here, our results are consistent with an increasingly common finding in the economics literature on low-cost, scalable interventions in education - namely, that such interventions are effective at nudging students toward taking relatively simple, one-time actions but are less effective at causing improvement in outcomes that require meaningful and sustained changes in student behavior. ${ }^{3}$ For example, text-messaging programs that push helpful information to students have proven effective at causing students to enroll in college once admitted (Castleman and Page 2015) or to renew financial aid (Castleman and Page 2016), but such programs have largely been unable to affect students’ academic outcomes, such as course grades or overall GPA (Fryer 2016; Castleman and Meyer 2016; Oreopoulos and Petronijevic 2018). ${ }^{4}$ Significant change in these outcomes is usually brought about by more comprehensive interventions that offer tutoring, advising, future planning, and some form of financial aid. ${ }^{5}$ We find that helping students create clear schedules and providing them with periodic reminders has no detectable effect on student grades or credit accumulation, an important finding for higher-education policymakers considering

\footnotetext{
${ }^{3}$ There are exceptions that find positive effects of low-cost interventions affecting sustained changes in behavior. For example, Chande et al. (2015) find that text message prompts to increase attendance in adult education programs, Patterson (2018) finds that commitment devices increase study time and improve performance in a Massive Open Online Course (MOOC), and Martinez (2013) finds positive effects of social cue interventions on students' performance in a MOOC.

${ }^{4}$ Our findings here contribute to the broader literature on planning interventions that shows encouraging people to make a concrete plan for action has shown promise in settings with a single action such as voting (Nickerson and Rogers, 2010) and getting the flu vaccine (Milkman et al., 2011), but has not shown to be effective in increasing sustained actions, such as attending the gym (Carrera et al., 2018).

${ }^{5}$ See, for example, Scrivener and Weiss (2013); Bettinger and Baker (2014); Andrews, Imberman, and Lovenheim (2016); and Evans, Kearny, Perry, and Sullivan (2017).
} 
the efficacy of programs that emphasize the importance of time management and sufficient study time.

Because our planning module requires students to set study-time goals, our results also contribute to the recent literature on goal-setting interventions. In a large field experiment among traditional college students, Clark et al. (2017) find that requiring students to make goals over course outcomes has a small positive effect on performance but that assigning task-based goals has a larger and more robust impact on course performance. The authors interpret their results as evidence that task-specific goals generate positive outcomes by addressing both present-bias and loss-averse preferences. In contrast, in another large field experiment in a traditional college setting, Dobronyi et al. (2017) find that asking students to make specific, meaningful, and attainable goals did not have any measurable impact on student outcomes. The authors also found that providing students with additional growth-mindset training (Dweck, 2006) and text/email reminders did not improve academic outcomes. ${ }^{6}$ Our results suggest that helping students set specific goals for study hours may not be an effective way to improve academic outcomes. ${ }^{7}$

The remainder of this paper is organized as follows: The next section offers a brief conceptual framework for thinking about why students encounter challenges with managing their study time well. Section 3 provides a detailed description of our intervention and its implementation at the UofT campuses and WGU. Section 4 describes the experimental data from both experiments and

\footnotetext{
${ }^{6}$ Dobronyi et al. (2017) base their work on research conducted by Morisano et al. (2010) and Schippers et al. (2015), which both find large positive effects of goal setting interventions.

${ }^{7}$ Our paper also relates to the recent literature on pre-commitment devices in higher education. Himmler et al. (2017) find that asking students to pre-commit to taking exams at a certain time improved their overall performance in a graduate business school, while Baker et al. (2016) find that prompting students via email to schedule times to watch lecture videos in a Massive Open Online Course had no impact on performance. In a similar setting, Patterson (2015) finds that enabling students to pre-commit to limits on distracting internet time increased completion rates and improved performance but reminding students about their coursework and allowing students to block distractions while working had no significant impact on course outcomes.
} 
outlines our empirical strategy for estimating the treatment effects, while Section 5 presents the results. We discus and interpret our results in Section 6 and Section 7 provides concluding remarks.

\section{Conceptual Framework}

In this section, we outline the mechanisms through which our planning interventions could improve student outcomes, followed by a brief discussion of the potential obstacles to their effectiveness.

Many individuals tend to underestimate the time required to complete a task (Kahneman and Tversky 1979), with more complicated tasks, such as navigating university courses, usually resulting in greater underestimation (Buehler et al. 1994). Decomposing a task into smaller segments, however, helps individuals form more accurate estimates about the time required to complete it (Buehler et al. 1994; Forsyth and Burt 2008). Accordingly, to help students better appreciate the time they require and have available for the tasks in their courses, our planning interventions guide them through unpacking their weekly study schedules into smaller study sessions that are dispersed throughout the week.

We also remind students of their study goals and weekly completion benchmarks via text message throughout the academic year. The use of follow-up reminders is motivated in part by economic models of limited memory and inattention (Mullainathan 2002; Ericson 2014; Karlan et al. 2010), which predict that individuals are susceptible to inattention to their prior plans, thereby causing delays or even failures in plan completion. Reminders have been shown to successfully increase plan completion in a variety of domains, including exercise (Calzolari and Nardotto 
2012), repayment of loans (Cadena and Schoar 2011), savings accounts deposits (Karlan et al. 2010), and college matriculation (Castleman and Page 2015).

Our planning interventions are also designed to help students better manage their time by increasing 'implementation intentions,' a term that refers to the process of identifying when, where, and how one will fulfil a plan (Gollwitzer 1993). Recent experimental evidence suggests that fostering implementation intentions can increase desired behavior across many domains, including exercise, diet, recycling, project completion, and voting (Gollwitzer and Sheeran 2006; Nickerson and Rogers 2010). By requiring students to define implementation intentions at the beginning of the academic year, our planning intervention helps them establish clear study goals to follow while working through their courses.

As we describe in greater detail below, treated students at the UofT campuses were also assigned to a senior-undergraduate student coach, whose job was to check-in once a week via text message to inquire about how students were progressing and offer encouragement. Personal coaching or advising done over the phone or in person has proven effective in improving students' academic outcomes at both two-year and four-year colleges (Scrivener and Weiss 2013; Bettinger and Baker 2014; Oreopoulos and Petronijevic 2018). Despite there being less evidence on the effectiveness of personal coaching that occurs via text message, ${ }^{8}$ we offered treated students a textmessage coaching program to help them address any individual-specific challenges to following through with their plans.

\footnotetext{
${ }^{8}$ Oreopoulos, Petronijevic, Logel, and Beattie (2018) show that while personal coaching via text message did not improve academic outcomes in a sample of students at UofT, it did significantly and positively impact non-academic outcomes, such as student mental health and feelings of belonging at the university.
} 
There are, however, several reasons our planning interventions may be ineffective at increasing study time and improving students' academic outcomes. First, students' tendency to procrastinate may limit the efficacy of a planning intervention. Specifically, students may exhibit timeinconsistency and behave more impatiently in the moment than they had previously planned (Laibson, 1997; O’Donoghue and Rabin, 1999). Solomon and Rothblum (1984) find that more than half of college students report regularly procrastinating coursework. If present-biased preferences keep students from following through on their plans, then improving the quality of students' plans and reminding them about their plans may not be enough to affect academic outcomes.

Second, students may be overconfident in their abilities. Twenge et al. (2012) find that a majority of college students believe they have above average abilities. We also find a large majority of students believe they will perform above average compared to their classmates. If students overestimate their abilities, they may make insufficient study plans and underestimate the penalties they will face from failing to follow-through on their plans (Dunlosky and Rawson, 2012).

Third and finally, the benefits to studying are long-term, uncertain, and highly ambiguous. It is therefore also possible that students have low expectations on the returns to studying on grades, or the returns to grades on longer term outcomes. Perhaps obtaining a degree, for example, matters much more than obtaining a ' $\mathrm{B}$ ' average instead of a ' $\mathrm{C}$ '. Or perhaps these expectations are not correct. Motivating the benefits to studying or reducing ambiguity, may therefore increase study effort (Epstein and Halevy, 2018). 


\section{Description of Intervention}

In this section, we describe the implementation of the experiments at both UofT and WGU, providing greater detail about the planning interventions and the follow-up messages students received.

\subsection{The Intervention at UofT}

We conducted our experiment at UofT throughout the 2017-18 academic year. At both the main campus, UTSG, and the satellite campus, UTM, we partnered with all first-year economics instructors to include a 45 to 60 minute 'warm-up' exercise at the beginning of the course worth 2 percent of students' final grades. The exercise had to be completed within the first two weeks of the fall semester for students to receive course credit, with the type of exercise each student completed depending on whether he or she was randomly assigned to the treatment or control group. All students logged in using their university accounts and completed a brief introductory survey, in which they provided information about their parental education, their own expected educational attainment, their work plans, their educational history, and their self-reported tendency to procrastinate or become distracted. Students assigned to the treatment group were then required to complete an online module that first taught them about the importance of sufficient study time and then guided them through a planning intervention, while students assigned to the control group were given a personality test. Below we describe the treatment and control modules in more detail.

\subsubsection{Planning Intervention}


All students randomly assigned to the planning intervention at UofT completed a three-part online module. We offer an overview of the module in this subsection and provide full documentation in Appendix B.

During the first part of the planning module, we presented the college's recommendation for weekly study time (at least 4 to 6 hours per course, or at least 20 to 30 hours per week for a full course load) and information on the importance of sufficient study time for academic performance and general life satisfaction. We motivated the latter by showing descriptive evidence (gathered from previous experiments we ran at UofT) about the positive associations between study time and grades and study time and measures of mental health. In the second part of the module, we asked students to read testimonials from former students, each of which described a common challenge faced by university students and how making a schedule and studying regularly can help students avoid these pitfalls. After reading through the stories, students wrote about how they could motivate themselves to stick to a regular study routine and identified the study strategies they thought would be the most helpful for doing so. Students were encouraged to slow down or write a little more if they tried to continue through the exercise below a minimum time or wordcount restriction.

Having discussed the importance of keeping an organized schedule and studying enough, the third part of the online module asked students to make their own weekly schedule by building a weekly calendar. We first asked students to populate their calendars with class times, which they could do by downloading a standard electronic calendar (ICS) file from their university platform and then uploading the ICS file to our platform. Students then scheduled their anticipated job schedules along with their regular sleep routines. Once they had accounted for items with little scheduling flexibility, students were asked to populate their calendars with weekly study times. 
The module asked them to reconsider the importance of sufficient and regular study time and would not allow them to proceed unless the number of scheduled study hours throughout the week matched their self-imposed target for study hours. As the final step toward completing their calendars, students scheduled personal time for seeing friends and family and engaging in other activities they enjoy.

To help students stay on track throughout the academic year, we made their weekly calendars available to them. If students already had a Gmail account, they simply had to provide their Gmail address and we then uploaded their calendars directly into their Google calendars. If students did not have a Gmail account, we gave them the option to create one or to simply download their calendar as an ICS file and upload it to whichever calendar application they prefer to use. ${ }^{9}$

For the last step of the exercise, all students were encouraged to enroll in a virtual coaching program calledYou@UofT. ${ }^{10}$ We explained that students would be matched with an experienced, senior-undergraduate coach whose job would be to check-in once a week via text message to inquire about how students were doing with their study goals, offer support and encouragement, and answer any questions. Across both campuses, 80 percent of students opted-in to the coaching program by providing their cell phone numbers.

Our coaches were hired through a research opportunity program, which allows students to participate in a research project for course credit (rather than pay). Coaches were solicited to apply for the program through various student service offices and we sought recommendations for keen,

\footnotetext{
${ }^{9}$ A total of 1,685 students completed the planning intervention at UofT and 1,424 (84.5 percent) provided a Gmail address for us to upload their calendars directly into their Google calendars. The remaining students downloaded their calendar from our platform as ICS file.

${ }^{10}$ As in Oreopoulos and Petronijevic (2018), we chose the name to emphasize that the program would help coach students toward their individual definitions of success.
} 
talented senior undergraduates who had prior experience helping new students (as, for example, residence dons, orientation volunteers, or tutors). Upon joining the team, coaches reported to our program manager, a graduate student in economics, who communicated best practices and ensured proper protocol was being followed.

Once students opted-in to the coaching program, they were assigned to a specific coach and each coach was assigned a few time slots during the week to be the coach who was on call. During each on-call time for a given coach, we sent a batch message to all students who were assigned to that coach to spur productive conversation. If students replied while their coach was still on call, that coach would continue the conversation. If students replied after their coach's shift ended, the coach who was currently on call or the team manager was responsible for closing the conversation.

The batch messages we sent to students fell into two general categories. The first message type consisted of a weekly study tip on how to use study time effectively. When sending these messages, we took advantage of knowing when students planned to study from the calendars they completed, sending the messages 15 minutes prior to one randomly selected study session. The second type of message was a weekly check-in from the students' coaches, which was designed mostly to offer support and inquire about how well students were managing their time. To help effectively close conversations, we sent an automatic follow-up message with a tip or encouragement if the student did not respond to the original check-in message. A list of example check-in text messages that we sent throughout the academic year is available in Table C1 in Appendix C.

Student engagement with the text-messaging program was quite high, with 26 to 66 percent of treated students responding to our messages each week. In terms of cumulative engagement, 80 
percent of treated students sent at least one text message back to their coach during the academic year. We also asked students via text message for feedback on our coaching program, and many expressed gratitude and appreciation for the study tips and support. ${ }^{11}$

\subsubsection{Personality Test}

As in Oreopoulos and Petronijevic (2018), students who were assigned to the control group at both UTSG and UTM were given a personality test measuring the Big Five personality traits of agreeableness, conscientiousness, extraversion, openness to experience, and emotional stability. The test tended to take about 45 to 60 minutes to complete, and students were emailed a report describing their scores on each trait upon completion of the exercise. Beattie, Laliberté, and Oreopoulos (2018) describe the personality test in greater detail in the appendix of their paper and use the resulting data to explore non-academic predictors of performance in university.

\subsection{The Intervention at WGU}

In this subsection, we provide an overview of the planning module students completed at WGU. Full documentation is presented in Appendix B.

WGU is a large non-profit online college in the United States. ${ }^{12}$ Prior to the beginning of his or her first semester, each new student participates in an online student orientation. As part of our experiment, randomly-selected undergraduate students who enrolled between January 2 and

\footnotetext{
${ }^{11}$ An anonymized list of student response to our feedback request and more detailed information on student engagement with the text-messaging program are available upon request.

12 See Appendix A for a broad overview of WGU.
} 
March 1 of 2017 were additionally required to complete a two-part planning module at the end of the online orientation. ${ }^{13}$ The planning module was similar to that which was completed by students at UofT.

In the first part, we again shared the college's recommendation for weekly study time (1-2 hours per "competency unit"/credit or 3-6 hours per typical course) $)^{14}$ and required students to complete an interactive weekly planning activity, in which they allocated their time among four categories (work, study, recreation, family and home) and 21 subcategories. ${ }^{15}$ Upon completion of the planning exercise, the second part of the module asked students to organize the collegeassigned Google calendar associated with their WGU email account. This calendar was prepopulated with categorical events from each of the four primary activity types and students were required to organize the calendar to match their planning activity allocation. When students finished organizing their calendars, they submitted a screenshot of their completed calendar as an enrollment requirement.

With each student having a completed calendar in hand, WGU recreated study events onto treated students' calendars each week for the remainder of the semester. Students were able to modify their study schedules at any time, with study events being visible on students' Google calendars, the calendar in the WGU student web portal, and the WGU mobile application. The 81.8 percent of students who installed the WGU mobile application also received mobile notifications 15 minutes prior to two randomly selected study sessions between 9am and 8pm each

\footnotetext{
${ }^{13}$ Students in the control group only completed the regular online orientation.

${ }^{14}$ Among students taking 5 courses, this recommendation amounts to 15 to 30 hours per week of total study time, which is very similar to the recommendation at UofT of 20 to 30 hours.

${ }^{15}$ Work- working, commuting, and other work time; study--mentor support, course readings, course writing, group activity, and other study time; recreation-watching tv, socializing, reading, exercise and sports, browsing the internet, and other recreation; and family and home-caring for family, preparing and eating meals, cleaning and laundry, household management, lawn and garden, sleep, and other home and family.
} 
week. Additionally, all treated students received study notifications in the WGU web portal “notification center.”

To help students unpack their semester schedules, we also populated their calendar with “completion benchmarks.” WGU students digitally meet with a counselor to set their course schedules prior to the beginning of each semester. In this meeting, they outline the anticipated start and end dates for each course. Nearly all courses at WGU have a "Course of Study Guide" or syllabus that divides the course into 4-8 segments or blocks. We combined students' anticipated start and end dates with their course syllabi segments to create evenly spaced intermediate completion benchmarks for each course in which a student is enrolled. These benchmarks were populated in students' WGU Google calendars and automatically adjusted to any changes made by WGU or the students to the scheduled start or end date in WGU's system. Students could view these benchmarks in the Google calendar, WGU web portal, and WGU mobile app, and students with the mobile application received a reminder at 4pm two days before each completion benchmark, reminding them that they would need to complete their benchmark task in the next two days to stay on track. ${ }^{16}$ Examples of the benchmark reminders can be found in Table C2 in Appendix C.

\section{Data, Motivating Evidence, and Empirical Strategy}

In this section, we describe the data we collected from UTSG, UTM, and WGU, along with our strategy for estimating treatment effects across the three sites.

\footnotetext{
${ }^{16}$ These completion benchmark notifications were also displayed on all WGU student's web portals.
} 


\subsection{Experimental Randomization and Sample Description at UofT}

We begin the description of the data at UofT with Table 1, which reports the total number of students in the treatment and control groups, as well as the fractions of students sorted to treatment and control at each campus. Prior to the experiment, we intended to sort one third of students to both the treatment and control groups at $\mathrm{UTSG}^{17}$ and to evenly divide students across treatment and control groups at UTM. Table 1 shows that slightly more than one third of students (35.8 percent) were sorted to the treatment group and slightly less than one third (30.4 percent) were sorted to the control group at UTSG, while we reached our target fractions at UTM, as the percentages of students sorted to treatment and control are not statistically different than 50 percent. Across both campuses, we have 3,581 students in our study, with 2,044 coming from UTSG and 1,537 coming from UTM. The completion rates for the online modules are very high across both campuses, ranging between 97 and 98 percent. We can match 94 percent of our experimental sample to the university's administrative data on course grades, leaving us with an analysis sample of 3,344 students. ${ }^{18}$

Tables 2 and 3 present balancing tests UTSG and UTM, respectively, showing that the treatment and control group are balanced along observable characteristics. The lone exception (out of 32 tests for mean differences) is that students in the treatment group at UTM report being slightly more likely to often think about their futures. We demonstrate below that our treatment effect estimates are robust to controlling for this variable and many other covariates.

\footnotetext{
17 The remaining one third of students was sorted to a different treatment group, which is the subject of a separate, standalone paper.

18 The university's grades data only include students who are registered at the end of September in the fall semester of 2017, which is why we are unable to match a small fraction of students who are no longer registered at that time. The match rate to the grades data is not differential by treatment status.
} 
In terms of the sample characteristics, approximately half our sample at the UofT campuses is male, the average student is 18 years old, approximately 40 percent of students speak English as their first language, 50 percent of students are international, and approximately 75 percent are in their first year of studies. These characteristics are similar across UTSG and UTM. Differences start to emerge, however, when one considers variables related to academic preparedness. The average incoming high school grade average at UTSG is 91 percent, while it is 85 percent at UTM, reflecting the differences in selectivity across the two campuses. The $75^{\text {th }}$ percentile student at UTM has a high school grade average of 88 percent, which corresponds to the $25^{\text {th }}$ percentile student at UTSG. Also consistent with differences in selection criteria, many students at both campuses intend to earn at least an A-grade average and more than a bachelor's degree, but the factions are higher at UTSG (74 percent and 48 percent) than at UTM (62 percent and 40 percent). It is also the case that only 23 percent of the UTSG sample consists of first-generation students, while the fraction is considerably higher at UTM, at 34 percent.

With respect to student time commitments, the average student at UTSG expects to study approximately 18.6 hours per week in university, work approximately 6.4 hours a week for pay and spends approximately 24 minutes commuting to campus (in one direction). At UTM, students expect to study 15.6 hours per week, work 8.2 hours for pay and spend 31 minutes commuting to campus. ${ }^{19}$ On average, students at UTSG and UTM report spending 13.6 and 11.8 hours per week, respectively, studying outside of class in high school. In subsection 4.3, we provide descriptive evidence on student study times during the fall semester at UTSG and UTM, along with the associations between study time and academic performance.

\footnotetext{
${ }^{19}$ Note that the expected study time per week is collected during the baseline (pre-randomization) survey for both treatment and control group students. This variable differs from the actual (self-reported) study time, which appears in Figure 1 and is gathered during the follow-up survey at the end of the semester.
} 


\subsection{Experimental Randomization and Sample Description at WGU}

At WGU, our study sample includes 6,065 undergraduate students who enrolled between January 2 and March 1 of 2017. Students were randomly assigned to either the treatment or control group based on the last two digits of their sequentially assigned student number. Table 4 shows the balance of observable characteristics across treatment and control, indicating that the groups are mostly balanced in terms of observable characteristics. Among the 16 characteristics presented in the table, four are statistically different across treatment and control groups. Students in the treatment group are approximately half a year older, 2 percentage points more likely to work full time, 2 percentage points more likely to have annual incomes between $\$ 45,000$ and $\$ 65,000$, and 2 percentage points more likely to be first-generation students. While there are more statistically significant differences than one would expect from random assignment, we are able to verify that the treatment assignment mechanism was followed in over $99.9 \%$ cases. ${ }^{20}$ Furthermore, these differences are not economically large, and we show below that controlling for these variables (and many other covariates) does not affect our estimated treatment effects. Finally, our experimental design also involved randomly assigning graduate students to the planning treatment. ${ }^{21}$ While our analysis plan specified that these graduate students be dropped from our analysis, we show in Appendix D that our sample balances across observable characteristics (1/16 variables differ at the 5\% level) when graduate students are included and that our results remain unchanged.

\footnotetext{
${ }^{20}$ Based on the last two digits of student's id numbers, only 4/6065 are assigned to a treatment group that does not correspond to the assignment rule. Our estimates are robust to exclusion of these observations.

${ }^{21}$ Graduate students assigned to the treatment were not sent benchmark reminders in all courses, but were otherwise treated identically to undergraduate students.
} 
In terms of the sample characteristics, approximately 34 percent of the WGU students in our study are male and the average student is 35 years old - a marked difference from the UofT sample, where half of the sample is male, and the average student is only 18 years old. Nearly 80 percent of the sample consists of white students, while Hispanic and black students each comprise approximately 11 percent of the sample. A large majority (75 percent) of students are employed full time and many (40 percent) have annual incomes of $\$ 65,000$ or more. ${ }^{22}$ Approximately 42 percent are first-generation students whose parents did not complete post-secondary education.

\subsection{Descriptive Facts on Student Study Time at UofT and WGU}

Figure 1 (discussed above in the Introduction) shows that many students at UofT study far less than the time they have available to do so, with the median student reporting that they studied only 12 hours per week in the fall semester despite having more than 90 hours available. As mentioned, we construct time available in Figure 1 using the information students provide in our baseline survey about their expectations for upcoming weekly hours of work (for pay), commuting time to and from campus each week, time spent attending lectures each week, and time spent sleeping. ${ }^{23}$ We gathered information on actual (self-reported) study time during the fall semester by conducting a follow-up survey with students at the end of the fall semester, asking how many hours they spend studying outside of class during an average week (which is the reported study time variable in Figure 1) and how many hours they spend studying during a week in which they are

\footnotetext{
${ }^{22}$ One may be concerned that students who work full time do not have available time to increase study intensity. In our analysis of heterogeneous treatment effects below, we show that our estimates do not differ across WGU students by employment status or household income.

${ }^{23}$ We acknowledge that there are other demands on students' time that are not captured by these variables, such as eating, sports and clubs, self-care, church going, etc. To make sure that we are not drastically overstating the time students have available, we have also done calculations where we conservatively assume that students only have 60 hours per week for being productive in school. Taking 60 hours per week as the total available time and subtracting time spent working (for pay), commuting, and attending class, the median student still has 41 hours remaining and 90 percent of students have at least 27 hours per week remaining.
} 
preparing for midterms or exams. ${ }^{24}$ Because the follow-up survey did not have grade incentives attached, the aggregate response rate was only 48 percent, with 47 percent of students responding at UTSG and 50 percent of students responding at UTM. However, attrition from the follow-up survey was not differential by treatment status at either campus.

In Figure 2, we quantify the amount of available time students at UofT are not using toward studying by subtracting reported study time from available time and plotting the resulting distribution of remaining time. ${ }^{25}$ The vertical lines in the figure represent the $25^{\text {th }}, 50^{\text {th }}$, and $75^{\text {th }}$ percentiles, respectively, indicating that three-quarters of students expect to forgo at least 65 hours per week in potential study time, 50 percent of students expect to forgo at least 78 hours, and onequarter of students expect to forgo more than 87 hours a week. We note again that these calculations already account for sleeping time, class time, and self-reported expectations for time required for working and commuting to and from school each week. ${ }^{26}$

Table 5 presents summary statistics for self-reported student study time at UTSG and UTM in the fall semester during a typical week and during a week spent preparing for midterms or exams. Across both campuses, the average student in the control group reports having spent only 15.6 hours outside of class studying during average week in the fall semester. ${ }^{27}$ During a week of preparing for midterms or exams, students report studying 24.8 hours, on average - an increase of nearly 10 hours from a typical week but still only marginally more than the number of hours one typically spends at a part-time job. In terms of the breakdown across campuses, students at UTSG

\footnotetext{
${ }^{24}$ The sample in Figure 1 is restricted to students in the control groups across both campuses of UofT.

${ }^{25}$ We construct this figure by restricting the sample to students in the control group and pooling together students at UTSG and UTM.

${ }^{26}$ Using the more conservative calculation that assumes students only have 60 hours per week for being productive in school (see footnote 19), the median student expects to forgo 26 hours per week and 75 percent of students expect to forgo at least 14 hours per week.

${ }^{27}$ We focus only on students in the control group in this subsection, deferring an exploration of whether treatment significantly increased student study time to Section 5.
} 
study more than those at UTM: the average student at UTSG reports studying 16.8 hours, on average, during a regular week and 28.1 hours during a week before exams, while the average student at UTM reports studying 14 hours during a regular week and 20.1 hours before exams.

The survey evidence implies that students at UTSG and UTM study relatively little, which raises the question of whether students could meaningfully improve academic outcomes by increasing study time. In Figure 3, we pool the control groups across both campuses and plot descriptive associations between self-reported hours spent studying during a typical week in the fall semester and the average grade across all courses taken in that semester, the GPA earned across all courses, and the number of credits earned. We also plot the associated linear relationships, estimated on the underlying student-level with regressions that include campus fixed effects. The estimated coefficients from these regressions are reported in columns (1) and (3) of Panel A in Table 6.

All relationships are positive and statistically significant, implying that an increase in weekly study time of one standard deviation (13 hours) is associated with an increase in average course grades of 11.5 percent of a standard deviation, an increase in GPA of 13.6 percent of a standard deviation, and increase in credits earned of 11 percent of a standard deviation. These relatively small magnitudes are likely biased downward by measurement error in study time attenuating the relationships, as student study time is self-reported retrospectively. To mitigate the attenuation bias, we instrument for weekly study time using the following variables from the baseline survey: study hours per week in high school, self-reported expected study hours per week this semester, tendency to regularly “cram” for exams, expected hours per week working for pay during the semester, and expected commuting time to campus. The IV estimates, reported in columns (2) and (4) in Table 6, are appreciably larger than the OLS estimates, indicating that a one standard 
deviation increase in study time is associated with an increase in mean grades and GPA in the fall semester of 22 and 21 percent of a standard deviation, respectively. ${ }^{28}$

In Panel (B) of Table 6, we focus only on the relationship between weekly study time and grades in math or economics courses. We do so to address concerns about grade inflation attenuating the relationship between study time and course grades, relying on the notion that grading in math and economics courses is likely to be more objective than in other social science or humanities courses, resulting in a tighter link between student effort and outcomes. This is indeed what we find, as the IV estimates indicate that a one standard-deviation increase in weekly study time is associated with an increase in the mean math and economics grade of 37 percent and 30 percent of a standard deviation, respectively. Taken together, the descriptive relationships that adjust for measurement error indicate that an additional 10 hours of studying per week is associated with an increase in mean grades between 2.2 and 4.6 percentage points. Although these estimates do not reflect a causal relationship, the descriptive relationship between studying and grades is small when comparing only marginal differences in studying. Large differences - more than 10 hours a week - are needed, all else equal, to observe changes in letter grades (i.e., moving from a B grade to an A grade). We return to this point in Section 6 below, where we interpret our treatment effects.

\footnotetext{
${ }^{28}$ Brint and Cantwell (2008) also use retrospectively self-reported study time from the University of California Undergraduate Experience Survey to show that a one standard-deviation increase in weekly study time is associated with an increase in GPA of 10 percent of a standard deviation, an estimate that is very close to our OLS estiamte. Accounting for measurement error in retrospective self-reports, Stinebrickner and Stinebrickner (2004) use time-diary data collected at six different times during the academic year at Berea College to estimate that a one standard-deviation increase in daily study time is associated with a 0.43 standard deviation higher college GPA. The authors also find evidence of non-linear effects on study time on grades, where the effect of study time is diminishing. We tested for non-linear effects by adding a quadratic study time term in each of the specifications in Figure 3, but the quadratic terms were not significant in any specification. To compare the estimates from Stinebrickner and Stinebrickner's daily study time data with those from our weekly data, note that the standard deviation of daily study time in their data is 1.62 hours per day (or 11.34 hours per week) and the standard deviation of GPA is 0.686 points. In our data at UofT, the standard deviation of study time is 13 hours per week and the standard deviation of GPA is approximately 1 point.
} 
Turning to the relationship between study intensity and student outcomes at WGU, we note that we are unable to directly observe the frequency and duration of study time because course content is hosted on third-party platforms. However, students are able to access all of their courses through the WGU portal and we observe how frequently students visit this portal. Although these data do have limitations, they provide a measure of engagement that does not suffer from problems related to retrospective self-reporting.

The data suggest that students taking courses online with WGU study infrequently. Figure 4 shows the distribution of the number of days per week that students log into WGU's online portal. The average student logs into the WGU portal 2.1 days per week. In addition, 90 percent of students log in less than 3.7 days per week and 18.5 percent of students log in less than 1 day per week. While it is possible that students are not always accessing course material via the WGU website, the log-in data indicate that many students access materials on WGU's portal quite infrequently. In Figure 5, we plot the correlation between days logged in per week and credits earned. We find a strong and statistically significant positive relationship between log in activity and credits earned, with a one standard deviation increase in days logged in per week (1.3 days) correlating with a 51.3 percent of a standard deviation increase in credits earned.

The descriptive evidence implies that many students at all three experimental sites study quite little, with large slack for increasing study intensity but potentially low returns from doing so. We explore whether our planning intervention was effective at increasing student study time and academic outcomes in Section 5 and discuss and interpret our results in Section 6.

\subsection{Empirical Strategy for Estimating Treatment Effects}


Having successfully randomized students across treatment and control groups at UTSG, UTM, and WGU, we estimate the effects of the planning treatment with a comparison of mean outcomes in a simple regression framework. The main specification, which we estimate separately at each site, is given by

$$
y_{i}=\beta_{0}+\beta_{1} \text { Treatment }_{i}+\rho^{\prime} X_{i}+u_{i}
$$

Here, the outcome of student is regressed on an indicator for the student being assigned to the treatment and, in some specifications, additional student-level control variables.

The main parameter of interest is $\beta_{1}$, the estimated effect of the planning treatment. This parameter represents an Intent-to-Treat effect, as students are included in the treatment group regardless of whether they completed the online exercise, took it seriously, provided their phone number, responded to a coach, or used their weekly calendar. Given that our completion rates and opt-in rate are quite high, these estimates are likely close to the average treatment effect of completing the exercise. ${ }^{29}$

With respect to outcomes, at UofT, our main outcomes of interest are course grades, overall grade point average (GPA), the number of credits attempted, the number of credits earned, and persistence into second semester. At WGU, our main outcomes of interest are the number of credits attempted, the number of credits earned, the number of days until a student completed his or her first credit, and retention. ${ }^{30}$ When the outcome of interest is course grades, we stack all course grades and run a regression at the student-course level, clustering standard errors at the student

\footnotetext{
${ }^{29}$ Recall that 97 percent of students completed the online exercise at the UofT campuses. In addition, 80 percent of students who were invited to participate in the text-messaging program provided a phone number. All students who were assigned to the treatment group at WGU were required to complete the planning module and submit a screenshot of their study calendar as a condition of enrollment. The enrollment module at WGU does not allow students in the treatment group to advance until they have completed these steps.

${ }^{30}$ We do not include grades as an outcome at WGU because WGU does not give traditional grades in courses. Instead, all courses at WGU are graded as pass/fail.
} 
level. The effects on all other outcomes are estimated with regressions at the student level and robust standard errors are reported.

\section{Results}

In this section, we present the estimated effects of the planning treatment on student self-reported study times (at UofT), online activity (at WGU), and academic outcomes (at both UofT and WGU), as well as an exploration of heterogeneous treatment effects across various student subgroups.

\subsection{Treatment Effects on Student Self-Reported Study Time}

We begin by discussing treatment effects on student self-reported study time from the follow-up survey at UofT and activity on the online portal at WGU.

The average student in the control group at UofT spent 15.6 hours studying outside of class during a regular week in the fall semester and 24.8 hours studying when exams were approaching. Table 7 reports estimated treatment effects on both outcomes in the full sample of UofT students and separately by campus. The estimated average treatment effects are presented, with and without control variables, respectively, in columns (3) and (4). Treatment effects on study time during a regular week in the pooled sample range between 1.65 and 1.69 hours and are statistically significant at the 1 percent level. Students who were assigned to the planning treatment therefore self-report studying nearly two more hours during a regular study week than non-treated students and treatment effects are nearly identical across UTSG and UTM, as in indicated in the bottom two panels of Table 7. The estimates in Table 7 also reveal that the planning treatment did not affect student study time during exam or midterm periods, on average, as the effects are small and statistically insignificant in all specifications and across both campuses. 
In Figure 6, we further investigate the underlying patterns in the treatment effects throughout the distribution of students by plotting separate densities by treatment and control group for student study time during an average week and for study time during a week with midterms or exams approaching. The average treatment effect on study time during an average week (reported above) appears to stem from the planning intervention causing fewer students to self-report studying less than 15 hours per week and more students to report studying between 15 and 45 hours per week. The patterns for the densities of study time during an exam period are less clear, as the planning module resulted in more students reporting studying between 17 and 37 hours but fewer students studying above 50 hours. Because of these competing forces, the estimated average treatment effect is not statistically differentiable from zero.

In addition to study hours at UofT, we test whether the treatment at WGU affected study frequency as measured by logins and click data. The main outcomes of interest are the number of days per week a student logs into WGU's online portal and the log number of mouse clicks, log number of mouse moves, and log number of page scrolls. Although these data have limitations because students are primarily studying outside of the WGU website, they do contain precise information on frequency and intensity of student interaction with the online portal. Table 8 shows that for all four outcomes the effects of intervention are small and statistically insignificant. Figure 7 underscores this point, showing that the average number of days students log into the WGU website during each week of the semester do not significantly differ across the treatment and control groups.

In sum, we find clear evidence that assignment to the planning-focused warm-up exercise at UofT caused an increase in self-reported study time during an average week and suggestive evidence that it also caused an increase in study time during midterm and exam periods. However, 
we do not find evidence that treated students at WGU significantly changed their study time in response to the intervention. There are at least three reasons for the contrasting results between UofT and WGU. First, it is possible that the intervention was effective in the UofT sample but not the WGU sample. Second, WGU students may have increased study time but we are not able to detect it given the limitations of our study time data at WGU. Third, treated students at UofT may have been primed by the treatment materials to inflate their self-reported weekly study time relative to students in the control group. In Section 6, we present supplemental evidence to suggest that treated students being primed is an unlikely explanation for our results, showing that we obtained nearly identical estimates after running a similar experiment the subsequent year at the same UofT campuses. We also use new data from the follow-up experiment to present additional evidence against the priming interpretation of our results.

\subsection{Treatment Effects on Achievement Outcomes}

Table 9 reports treatment effects for several academic outcomes estimated separately at UTSG, UTM, and WGU. Outcomes at UofT are measured throughout the entire 2017-18 academic year, while outcomes at WGU are recorded for all students who enrolled between January 2 and March 1 of 2017. We define the 'retention' outcome as a binary variable capturing whether a student was enrolled in the winter semester of the 2017-18 academic year at UofT and whether a student was enrolled in the semester following the experimental period at WGU.

The planning treatment appears to have no effect on students' academic outcomes. The results in Table 9 indicate that treated students do not attempt or earn more credits than students in the control group and they are not more likely to persist into second semester. These results are robust across all three experimental sites and to estimating treatment effects with and without other 
student-level control variables. ${ }^{31}$ At WGU, there is suggestive evidence that treatment may have actually reduced retention into next semester, with students in the treatment group being 1.5 percentage points less likely to enroll. This is a small effect, however, corresponding to 1.7 percent of the mean retention rate.

In Table 10, we investigate treatment effects on course grades and GPA at the UofT campuses and the number of days until a student earns his or her first credit at WGU. At UofT, we show treatment effect estimates on course grades from stacked regressions where the unit of observation is a student-course and standard errors are clustered at the student level. We also present estimated treatment effects on courses taken during the fall semester, courses taken during the winter semester, and all courses taken during the full academic year. ${ }^{32}$ When the outcome is student GPA from the full academic year, we run the regression at the student-level and report robust standard errors.

The planning intervention did not significantly affect student grade outcomes at either campus of UofT. This result is robust to considering courses from each semester separately and to including additional control variables. Similarly, at WGU, we find that the planning intervention did not have any impact on the number of days students needed to complete their first credit. We provide a more detailed discussion of these estimated null effects in Section 6 below, where we interpret and reconcile these results with the effects of treatment on study time.

\footnotetext{
${ }^{31}$ At UTSG and UTM, control variables include student age, self-reported study hours per week during high school, expected hours per week studying this semester, expected paid-work hours per week, tendency to think about future goals, tendency to study at the last minute, difficulty transitioning to university, commuting time (in minutes) to campus, and indicator variables for first-year status, international student status, first-generation status, gender, English mother-tongue status, a self-reported desire to earn more than an undergraduate degree, and a self-reported expectation to earn an A- average grade or greater. At WGU, control variables include age, sex, race, first generation status, employment status, and income (bins).

${ }^{32}$ Courses from the entire academic year include fall semester courses, winter semester courses, and courses that span both semesters.
} 


\subsection{Treatment Effects Across Student Subgroups}

We now present estimated treatment effects on academic outcomes across a variety of student subgroups. ${ }^{33}$ Specifically, at both the UofT campuses and WGU, we investigate whether treatment effects are differential by student gender, age, employment status, and first-generation status. At the UofT campuses, we also explore potentially different treatment effects across international and domestic students and first-year and non-first-year students; while at WGU, we also differentiate across students by race and by household income.

In Tables 11 and 12, we report the effects of the planning intervention on all course grades across student subgroups at UTSG and UTM, respectively. The planning module does not appear to have caused an improvement in student grades among any subgroup of students at UTSG, as no treatment effect is economically or statistically significant. At UTM, treatment effects are negative and marginally statistically significant (at the 10 percent level) for male students and those who expect to work than 8 hours per week at the start of the academic year. However, given the many hypotheses being tested in the subgroup analyses across UTSG and UTM (24 hypothesis) and the lack of an overall treatment effect in the main sample, we interpret these negative effects cautiously, as they are likely due to chance.

Table 13 explores heterogeneous treatment effects on earned credits across student subgroups at WGU. As in the aggregate analysis, the planning module appears to have no effect on credit accumulation for any group of students. ${ }^{34}$ In particular, we note that there are no differences in treatment effects across students who are employed full-time, part-time, or

\footnotetext{
${ }^{33}$ In our analysis of subgroups (and treatment effects in the full sample above), we closely follow our AEA preregistered analysis plans (registration ID AEARCTR-0000972 at WGU and AEARCTR-0000810 at UofT).

${ }^{34}$ Treatment effects across subgroups on credit accumulation and persistence are similarly small and insignificant at both WGU and the campuses of UofT. The results are available upon request.
} 
unemployed, suggesting that the absence of a treatment effect in the full sample is not driven by students who work full-time not having the time available to increase their study effort. Treatment effects are also similar across students from households with different incomes.

Comparing the estimated treatment effects across all three experimental sites, treatment effects are similar across older (20 years of age or older at UofT and 30 years of age or older at WGU) and younger students, suggesting that student maturity (as proxied by age) is not an important factor in explaining our null treatment effects. It is also the case that treatment effects do not differ by first-generation status (at both UofT and WGU), international student status (at UofT), or firstyear status (at UofT), indicating that familiarity with institutional features is also unlikely to be an important moderating factor for treatment effectiveness.

\section{Discussion}

In this section, we discuss our seemingly contrasting results that treatment increased study time at UofT while having no effect on academic outcomes. We also discuss the implications of our results on the broader literature on student decision-making and interventions in higher education.

\subsection{Is the Effect on Study Time Real?}

Given the positive effects on study time at UofT and the null effects on grades, one may worry that the study time effect is biased upward by treated students being primed to inflate their selfreported study time relative to students in the control group. We argue that this is not the case, for three reasons.

First, supplemental evidence that we obtained from a similar experiment at the UofT campuses during the subsequent academic year (2018-2019) again shows nearly identical first stage effects on study time with subsequent null effects on academic outcomes. In the second experiment, 
treated students completed a slightly modified version of the planning intervention and were again invited to participate in follow-up text message coaching through the fall semester. ${ }^{35}$ Students were also given a follow-up survey at the end of the fall semester in which we asked them how many hours per week they spent studying during typical week and how many hours they spent studying during a week with midterms and exams approaching. ${ }^{36}$ This follow-up survey did have grade incentives attached in the second experiment, which resulted in a much higher completion rate of 70 percent. ${ }^{37}$ The supplementary evidence we present here thus suffers less from the potential concern that only the most motivated students completed the follow-up survey.

Estimated treatment effects on study time from the second experiment are reported in Table E.1 of Appendix E. In the pooled sample of students from both UofT campuses, treated students report studying approximately 2.2 hours more than control students during a typical week in the fall semester. The effect sizes are similar across the two campuses, with students at UTSG studying about 2.6 hours more per week (14 percent more than the control group) and students at UTM studying 1.7 hours more per week (10 percent more than the control group). Figure E.1 shows that the average treatment effect on study time again stems from the planning intervention causing fewer students to study less than 15 hours per week and more students to study between 15 and 45 hours per week. The results in Table E.1 are also consistent with treatment increasing extra study time during exam weeks at both campuses but these estimates are not statistically different from zero. $^{38}$

\footnotetext{
${ }^{35}$ Students in the control group were assigned to complete the same personality test.

${ }^{36}$ In contrast to the follow-up survey used in the first experiment, the question about midterms or exams asked students how many additional hours (relative to regular week studying) they study when midterms or exams are approaching.

${ }^{37}$ The completion rate was not differential between the treatment and control groups.

${ }^{38}$ The second experiment and its full set of results are the subject of a different, standalone paper. For brevity, we do not discuss the estimated treatment effects on academic outcomes from the second experiment in the current paper. In summary, we again do not find economically or statistically significant effects on academic outcomes, both in the full sample and many student subgroups.
} 
Second, to mitigate measurement error concerns that stem from retrospective self-reporting, we asked students in the second experiment to complete a time-use diary, documenting a complete breakdown of how they spent their time "yesterday" - that is, the day before they completed the follow-up survey. In addition to suffering less from measurement error, reported study time in the time-use diaries is also less likely to be biased by treated students inflating their answers, as the question did not ask students about study time directly. Instead, we simply asked students to provide a detailed breakdown of how they allocated their time the day before taking the survey, allowing them to select from 17 options, ${ }^{39}$ and then constructed total study time "yesterday" as the sum of time spent studying alone, time spent studying with other students, and time spent with a tutor or instructor (outside of class). We then estimated treatment effects on the amount of time students reported studying in their time-use diary, again recovering positive treatment effects at both campuses. Our estimated treatment effects, reported in Table E.2, imply that treated students studied about 0.25 hours more per day, on average, than students assigned to the control group, which amounts to approximately a 6 percent increase in study time relative to the control group mean. The estimated effects on study time are similar across UTSG and UTM and, at approximately 15 minutes per day, align very closely with our estimates for treatment effects on self-reported weekly study time. ${ }^{40}$

Third, although we did not find positive treatment effects on our measures of online activity at WGU, we note that these measures are imperfect proxies for study time. In particular, we only

\footnotetext{
${ }^{39}$ The options were: sleeping, attending class, studying alone, studying with others, working for pay, meeting with a tutor or instructor, volunteering, commuting, seeing friends, spending time on a computer, spending time on a phone, watching TV, doing extracurricular activities alone, doing extracurricular activities others, eating alone, eating with others, and other activities not listed above.

${ }^{40}$ As further support for the intervention affecting study time, we note the subsequent experiment was also conducted at the third campus of UofT, the University of Toronto at Scarborough, and another large university in the great Toronto area, York University. Treatment effect estimates at both sites are similar to those reported here and are available upon request.
} 
observe activity (log ins, mouse clicks, mouse moves, and page scrolls) in the online portal that links students to external courses. ${ }^{41}$ Course content at WGU is hosted by third-party providers, which prevents us from observing actual study time and study intensity. Even if we did observe online coursework, it is possible that students complete much of their studying offline and simply access their online portals to download course materials. The estimated null effects on our measures of study activity at WGU therefore do not necessarily contradict the positive effects we find at UofT.

\subsection{Why is there No Effect on Grades?}

Given the positive and robust effect on study time at UofT, it is somewhat puzzling that we find no effect on grades. As noted earlier, however, the association between study time and grades (even after adjusting for measurement error in study time) is relatively weak. We found that an additional 10 hours of studying per week is associated with an increase in mean grades between 2.2 and 4.6 percentage points. We corroborate this finding again using the data gathered from our second experiment at UofT, where we can also instrument for weekly study time using total daily study time from the time-use diaries on the follow-up survey. The descriptive associations between study time and grades for the second experimental cohort are reported in Table E.3 in Appendix E and imply (using the IV estimates that are adjusted for measurement error) that an additional 10 hours of weekly study time is associated with an increase in mean grades between 2.25 and 4.93 percentage points, a range nearly identical the one found in our first experimental cohort.

Recall that our estimated treatment effect on weekly study time at UofT is approximately 1.7 hours per week. Evaluating this increase in study time at the estimated upper bound for the

\footnotetext{
${ }^{41}$ The online portal also includes a calendar, mentoring resources, testing resources, and financial resources.
} 
association between weekly study time and grades, we would expect to find an average effect on grades of 0.84 percentage points. This is a very small effect and one that we do not have the power to detect. ${ }^{42}$ Although our estimate of the return to studying is adjusted for measurement error, it does not reflect a causal link between study time and grades. We attempt to account for this by performing a back-of-the-envelope calculation that uses the estimate of the causal return to study time from Stinebrickner and Stinebrickner (2008), who use time-diary data from Berea College together with an instrumental variables strategy to find that a one-standard deviation increase in studying per day increases student GPA by 90 percent of standard deviation. ${ }^{43}$ The standard deviation of daily study time in their data is 1.62 hours per day (or 11.34 hours per week) and the standard deviation of GPA is 0.686 points. Importing their estimate of the casual return to studying into our setting, we would expect to find that increasing studying time by 1.7 hours per week (our treatment effect) leads to an increase in GPA of 0.09 points - an effect that would be marginally significant at the 5 percent level but still insignificant at the 1 percent level, given our statistical power. ${ }^{44}$

Taken together, our results imply that the planning intervention increased study time by approximately 1.7 hours per week at the UofT campuses but that the association between weekly study time and academic outcomes is not large enough for the treatment effect on study time to translate into an economically and statistically significant effect on course grades and GPA.

\footnotetext{
${ }^{42}$ In Table 10, the standard errors on our estimated treatment effects on fall semester grades are 0.584 and 0.735 percentage points and UTSG and UTM, respectively. The point estimates and standard errors together imply 95percent confidence intervals of $[-1.14,1.15]$ and $[-1.77,1.10]$.

${ }^{43}$ Stinebrickner and Stinebrickner (2008) instrument for study time with a variable indicating whether a student's roommate brought a video or computer game to campus.

${ }^{44}$ Pooling observations from both the UTSG and UTM campuses and including control variables along with campus fixed effects (all in order to increase statistical power) results in an estimated treatment effect of 0.002 points on fall semester GPA, with a corresponding 95-percent confidence interval of $[-0.068,0.073]$ and a 99-percent confidence interval [-0.091, 0.095].
} 


\subsection{Why Was the Intervention Unsuccessful and What Can We Learn from It?}

In this subsection, we argue that our intervention likely lacked the scale and intensity that are required to meaningfully affect student outcomes. We conclude the section by offering a speculative discussion about the implications of our results for future interventions.

\subsubsection{Students Did Engage with the Intervention}

UofT students engaged enthusiastically with both the online materials and the text message coaching program. With respect to the materials presented during the online intervention, treated students responded by initially scheduling more study time into their calendars than they reported expecting to study during the (pre-randomization) baseline survey. ${ }^{45}$ As shown in the first block of Table E.4 in Appendix E, the average treated student at UTSG scheduled 7 more hours than initially expected at the calendar stage while the average student at UTM scheduled 9.5 hours. Figure E.2 presents the densities of expected and calendar-scheduled study times for treated students at both UofT campuses, showing that treatment caused a rightward shift of the expected study time density, especially for those who planned to study 15 hours or less initially. These increases in planned study time again underscore that binding time constraints are not the reason most students do not study more, as many were able to allocate additional time in their weekly schedules for studying. Further, these results suggest students were reading and processing the materials presented to them during the intervention, as they increased planned study time by a large margin at the calendar building stage.

However, treated students did not follow through with their more ambitious study goals. The second block of estimates in Table E.4 show that the gains in calendar-planned study time over

\footnotetext{
${ }^{45}$ Importantly, the balancing tests in Tables 2 and 3 show that expected study time per week is not different across treatment and control groups.
} 
expected study time (at baseline) were completely undone during the semester, as students reported studying (at follow-up) 8.2 hours less than planned (at the calendar-building stage) at UTSG and 9.5 hours less than planned at UTM. ${ }^{46}$ Students were unable to follow through with their plans despite receiving weekly text messages that kept their study goals salient and offered help with on-going issues. As indicated in Figure E.2 in Appendix E, nearly 70 percent of students replied to these text messages at least once, with week-to-week response rates varying between 20 and 50 percent. Therefore, not only did students engage with the initial online intervention but many interacted with the text message coaching service as well. ${ }^{47}$

\subsubsection{The Intervention was Not Comprehensive Enough to Cause and Sustain the Required Change in Behavior}

Given that students seem to have been engaged with the all facets of the intervention, it is likely that the intervention simply did not have the scope and intensity needed to meaningfully affect student outcomes.

As shown above, the associations between study time and outcomes imply that marginal changes in study time are likely not enough to generate a large improvement in academic outcomes; instead, the descriptive relationships suggest large changes in study habits are required to meaningfully impact student grades. Furthermore, high-achieving students differ from lowachieving students along many characteristics other than study time. In Table E.5 in Appendix E,

\footnotetext{
${ }^{46}$ The final block in Table E.4 shows the estimated treatment effects on the difference between self-reported study time from the follow-up survey and expected study time at the baseline survey. Students in the control group at UTSG and UTM report studying 3.3 and 2.4 hours less than expected per week, respectively. The treatment effect at both campuses implies that the mean difference among treated students is approximately 2 hours larger, but it is important to note that treated students also studied less than expected.

${ }^{47}$ Supplemental evidence from our second experiment at the UofT campuses indicates that students enjoy participating in these types of coaching programs: 70 percent of participants agreed that the program was helpful for them and 87 percent thought the program should be offered again the following year to a new cohort of students.
} 
we restrict the sample to students from the control group across both UofT campuses and regress several different variables (gathered at baseline) on indicators for students having a fall semester course grade average that is an A or above, a B, a C, or a D and below (the omitted group). Students who earned an A average studied more than all other students and 7 hours more per week than students who earned a D average or less. This difference amounts to approximately 0.54 standard deviations of weekly study time.

But the remaining associations reported in Table E.5 indicate that there are much more stark differences between the best- and worst-performing students along other dimensions. For example, A students have incoming high school grades that are nearly a full standard deviation (0.95 SD) higher than students who earn a D or below, implying that much of the achievement gap is related to pre-existing differences in academic preparedness. In addition, top-performing students hold themselves to a higher standard, expecting to study 3.3 hours more than the worst students and being 18 percentage points (40 percent) more likely to expect to earn an A average in the upcoming semester. Relative to students who earn a D or less, students who earn an A average are also much more likely to believe that they (i) tend to finish what they start (16 percent), (ii) manage their time well (42 percent), (iii) do not study at the last minute for exams (23 percent), and (iv) think about the future (9.6 percent). They also start the online exercise approximately two days earlier at the beginning of the fall semester, which is consistent with them having a lower tendency to procrastinate (Beattie, Laliberte, and Oreopoulos 2018).

These descriptive associations, along with the evidence that treated students drastically failed to reach their calendar study goals, suggest that a more intense intervention is likely required to help students (i) compensate for lower incoming ability, (ii) set and maintain much more ambitious study goals, and (iii) meaningfully change their broader approach to post-secondary studies. Many 
successful interventions in post-secondary settings offer such exhaustive programs, consisting of a combination of tutoring, comprehensive and personalized advising, future planning, and some form of financial aid (Scrivener and Weiss 2013; Bettinger and Baker 2014; Andrews, Imberman, and Lovenheim 2016; Evans, Kearny, Perry, and Sullivan 2017). These efforts target a student's entire routine and approach to school, with personal support and frequent encouragement. Less comprehensive, low-touch interventions have proven effective at affecting outcomes that require students to take a series of well-defined steps (Castleman and Page 2015; Castleman and Page 2016), but such programs have largely been unable to affect outcomes such as grades or credit accumulation, which require sustained changes in behavior (Castleman and Meyer 2016; Oreopoulos and Petronijevic 2018).

\section{Conclusion}

In this study, we examine whether an intervention focusing on study time can improve student outcomes in three distinct academic environments: a selective four-year college, a less selective four-year college, and an online university. Our analysis is motivated by patterns of very low study times observed among students in our populations and documented by other scholars (e.g. Babcock and Marks, 2011). Despite recommendations to treat studying like a full-time job, students at the UofT campuses only report studying 16.8 and 14 hours per week, on average, at UTSG and UTM, respectively. Further, the median student at UTSG studies only 12 hours per week while the median student at UTM studies only 10 hours per week. At WGU students only $\log$ on to the course website an average of 2.1 days per week. Although students in each environment appear to have the ability to increase their studying, we find no impacts of our planning treatments on academic outcomes at any of the three academic environments we study and across many demographic subgroups. 
We find null effects on academic outcomes despite treated students being highly engaged with the intervention at the UofT campuses - with respect to both the online intervention and text message coaching - and responding to treatment by increasing study time by approximately 2 hours per week. The effect on study time was not large enough, however, to generate a significant change in academic performance, as our estimates of the relationship between study time and grades indicate that we would expect to see at most a 0.84 percentage point (6 percent of a standard deviation) improvement in course grades. Given the large change in study behavior that is required to generate meaningful change in student outcomes and the many other characteristics along which high- and low-performing students differ, it is likely that a more intense and comprehensive intervention that transforms students' approach and attitudes towards education is required to significantly improve academic achievement. 


\section{References}

Arum, Richard, and Josipa Roksa. 2011. “Academically Adrift: Limited Learning on College Campuses.” Chicago, IL: University of Chicago Press.

Andrews, Rodney J., Scott A. Imberman, and Michael F. Lovenheim. 2016. "Recruiting and Supporting Low-Income, High-Achieving Students at Flagship Universities.” NBER Working Paper \# 22260. Cambridge, Mass.: National Bureau of Economic Research.

Babcock Philip and Mindy Marks. 2011. “The Falling Time Cost of College: Evidence form Half a Century of Time Use Data.” The Review of Economics and Statistics. 93(2): 468-478.

Baker, Rachel, Brent Evans, and Thomas Dee, 2016, “A Randomized Experiment Testing the Efficacy of a Scheduling Nudge in a Massive Open Online Course (MOOC),” AERA Open, 2 (4)

Beattie, Graham, Jean-William P. Laliberté and Philip Oreopoulos. 2018. "Thrivers and Divers: Using Non-Academic Measures to Predict College Success and Failure," Economics of Education Review. 62: 170-182

Beattie, Graham, Jean-William P. Laliberté, Catherine Michaud-Leclerc, and Philip Oreopoulos. 2018. " What Sets College Thrivers and Divers Apart? A Contrast in Study Habits, Attitudes, and Mental Health," NBER Working Paper \# 23588. Cambridge, Mass.: National Bureau of Economic Research.

Bettinger, Eric, and Rachel Baker. 2014. "The Effects of Student Coaching: An Evaluation of a Randomized Experiment in Student Advising.” Educational Evaluation and Policy Analysis. 35(1):3-19. 
Bettinger, Eric, Sten Ludvigsen, Mari Rege, Ingeborg F. Solli, and David Yeager. 2018. "Increasing Perseverance in Math: Evidence from a Field Experiment in Norway.” Journal of Economic Behavior and Organization. 146: 1-15.

Bettinger, Eric, Lindsay Fox, Susanna Loeb, and Eric S Taylor, "Virtual Classrooms: How Online College Courses Affect Student Success," American Economic Review, forthcoming.

Brint, Steven and Allison M. Cantwell. 2010. "Undergraduate Time Use and Academic Outcomes: Results from the University of California Undergraduate Experience Survey 2006.” Teachers College Record. 112(9): 2441-2470.

Buehler, Roger, Dale Griffin, and Michael Ross. 1994. "Exploring the "planning fallacy": Why people underestimate their task completion times.," Journal of personality and social psychology, 67 (3),366.

Cadena, Ximena and Antoinette Schoar. 2011. "Remembering to Pay? Reminders vs. Financial Incentives for Loan Payments”. NBER Working Paper \# 17020. Cambridge, Mass.: National Bureau of Economic Research.

Calzolari, Giacomo and Mattia Nardotto. 2012. “Nudging with Information: A Randomized Field Experiment". CEPR Discussion Paper \# DP8671. London, UK. Center for Economic Policy Research.

Carrera, Mariana, Heather Royer, Mark Stehr, Justin Sydnor, and Dmitry Taubinsky. 2018 "The Limits of Simple Implementation Intentions: Evidence from a Field Experiment on Making Plans to Exercise." NBER Working Paper \# 24959. Cambridge, Mass.: National Bureau of Economic Research. 
Castleman, Benjamin, and Lindsay Page. 2015. “Summer nudging: Can personalized text messages and peer mentor outreach increase college going among low-income high school graduates?" Journal of Economic Behavior \& Organization, 115, 144-160. . 2016. "Freshman Year Financial Aid Nudges: An Experiment to Increase FAFSA Renewal and College Persistence.” Journal of Human Resources, 51(2): 389-415.

Castleman, Benjamin, and Katharine Meyer. 2016. “Can Text Message Nudges Improve Academic Outcomes in College? Evidence from a West Virginia Initiative.” Center for Education Policy and Workforce Competitiveness Working Paper \# 43. Charlottesville, VA: University of Virginia.

Clark, Damon, David Gill, Victoria Prowse, and Mark Rush. 2017. "Using Goals to Motivate College Students: Theory and Evidence from Field Experiments.” NBER Working Paper \# 23638. Cambridge, Mass.: National Bureau of Economic Research.

Doherty, William. 2006. “An Analysis of Multiple Factors Affecting Retention in Web-Based Community College Courses.” The Internet and Higher Education. 9(4): 245-255.

Damgaard, Mette Trier and Helena Skyt Nielsen. 2018. "Nudging in education.” Economics of Education Review. 64: 313-342.

Deslauriers, L., Schelew, E. and Wieman, C., 2011. "Improved learning in a large-enrollment physics class.” Science, 332(6031), pp.862-864.

Dobronyi, Christopher R., Philip Oreopoulos, and Uros Petronijevic. 2017. “Goal Setting, Academic Reminders, and College Success: A Large-Scale Field Experiment.” NBER Working Paper \#23738. Cambridge, Mass.: National Bureau of Economic Research. 
Dunlosky, J. and Rawson, K.A., 2012. “Overconfidence produces underachievement: Inaccurate self evaluations undermine students’ learning and retention.” Learning and Instruction, 22(4), pp.271-280.

Dunlosky, J., Rawson, K.A., Marsh, E.J., Nathan, M.J. and Willingham, D.T., 2013. “Improving students' learning with effective learning techniques: Promising directions from cognitive and educational psychology.” Psychological Science in the Public Interest, 14(1), pp.458.

Ericson, Keith M Marzilli, 2017. “On the Interaction of Memory and Procrastination: Implications for Reminders, Deadlines, and Empirical Estimation.” Journal of the European Economic Association, 15(3), pp.692-719.

Evans, William N, Melissa S. Kearney, Brendan Perry, and James X. Sullivan. 2017. "Increasing Community College Completion Rates among Low-Income Students: Evidence from a Randomized Controlled Trial Evaluation of a Case Management Intervention.” NBER Working Paper \# 24150. Cambridge, Mass.: National Bureau of Economic Research.

Larry G Epstein, Yoram Halevy. 2018. “Ambiguous Correlation,” The Review of Economic Studies, rdy008, https://doi.org/10.1093/restud/rdy008

Figlio, David, Mark Rush, and Lu Yin, "Is it live or is it internet? Experimental estimates of the effects of online instruction on student learning,” Journal of Labor Economics, 2013, 31 (4), 763-784.

Forsyth, Darryl K and Christopher DB Burt. 2008. “Allocating time to future tasks: The effect of task segmentation on planning fallacy bias," Memory \& cognition, 36 (4), 791-798. 
Fryer, Roland G. 2016. "Information, Non-Financial Incentives, and Student Achievement:

Evidence from a Text Messaging Experiment.” Journal of Public Economics. 144:109121.

Gollwitzer, Peter M. 1993. “Goal achievement: The role of intentions," European review of social psychology, 4 (1), 141-185.

Gollwitzer, Peter M, and Paschal Sheeran. 2006. “Implementation intentions and goal achievement: A meta-analysis of effects and processes," Advances in experimental social psychology, 38, 69-119.

Himmler, Oliver, Robert Jaeckle, and Philipp Weinschenk.. “Soft Commitments, Reminders and Academic Performance,” American Economic Journal: Applied Economics, forthcoming.

Kahneman, Daniel and Amos Tversky, 1979, “Prospect theory: An analysis of decision under risk," Econometrica: Journal of the econometric society, pp. 263-291.

Karlan, Dean, Margaret McConnell, Sendhil Mullainathan, and Jonathan Zinman. 2016. “Getting to the Top of Mind: How Reminders Increase Saving." Management Science, 62(2): 3393-3411.

Laibson, David. 1997. “Golden Eggs and Hyperbolic Discounting." The Quarterly Journal of Economics. 112(2): 443-478.

Lavecchia, Adam, Heidi Liu and Philip Oreopoulos. 2016. “Behavioral Economics of Education: Progress and Possibilities” Handbook of Economics of Education. (5): 1-74. 
Milkman, Katherine L., John Beshears, James J. Choi, David Laibson, and Brigitte C. Madrian. 2016. "Using implementation intentions prompts to enhance influenza vaccination rates." Proceedings of the National Academy of Sciences 108(26): 10415-10420.

Morisano, Dominique, Jacob B. Hirsh, Jordan B. Peterson, Robert O. Pihl, and Bruce M. Shore, 2010. "Setting, Elaborating, and Reflecting on Personal Goals Improves Academic Performance." Journal of Applied Psychology, 95(2): 255-264.

Mullainathan, Sendhil. 2002. “A Memory-Based Model of Bounded Rationality,” The Quarterly Journal of Economics, 117 (3), 735-774.

Nickerson, David W and Todd Rogers. 2010. “Do you have a voting plan? Implementation intentions, voter turnout, and organic plan making," Psychological Science, 21 (2), 194199.

O’Donogue, Ted and Matthew Rabin. 1999. "Do It Now or Later" American Economic Review, 89(1): 103-124.

Oreopoulos, Philip and Uros Petronijevic. 2018. "Student Coaching: How Far Can Technology Go?" Journal of Human Resources, 53(2): 299-329.

Oreopoulos, Philip, Uros Petronijevic, Christine Logel, and Graham Beattie. 2018." Improving Non-Academic Student Outcomes Using Online and Text-Message Coaching" NBER Working Paper \# 24992. Cambridge, Mass.: National Bureau of Economic Research.

Patterson, Richard W. 2018. “Can Behavioral Tools Improve Online Student Outcomes? Experimental Evidence from a Massive Open Online Course.” Journal of Economic Behavior and Organization, 153, 293-321. 
Schippers, Michaéla, Ad Scheepers, and Jordan Peterson, 2015. “A Scalable Goal-Setting Intervention Closes Both the Gender and Ethnic Minority Achievement Gap.” Palgrave Communications, 1: Article Number 15014.

Scrivener, Susan and Michael J. Weiss. 2013. "More Graduates: Two-Year Results from an Evaluation of Accelerated Study in Associate Programs (ASAP) for Developmental Education Students.” Policy Brief, MDRC.

Solomon, L.J. and Rothblum, E.D., 1984. Academic procrastination: Frequency and cognitivebehavioral correlates. Journal of counseling psychology, 31(4), p.503.

Stinebrickner, Ralph and Todd R. Stinebrickner. 2004. “Time-use and college outcomes.” Journal of Econometrics. 121: 243-269.

Stinebrickner, Ralph and Todd R. Stinebrickner. 2008. “The Causal Effect of Studying on Academic Performance.” The B.E. Journal of Economic Analysis \& Policy. 8(1): 1-55.

Twenge, J.M., Campbell, W.K. and Gentile, B., 2012. Generational increases in agentic selfevaluations among American college students, 1966-2009. Self and Identity, 11(4), pp.409-427.

Yeager, David, Carissa Romero, Dave Paunesku, Christopher S. Hulleman, Barbara Schneider, Cintia Hinojosa, Hae Yeon Lee, Joseph O’Brien, Kate Flint, Alice Roberts, and Jill Trott. 2016. “Using Design Thinking to Improve Psychological Interventions: The Case of the Growth Mindset During the Transition to High School.” Journal of Educational Psychology. 108(3):374-391. 


\section{Tables}

Table 1: Randomization Design at UofT

\begin{tabular}{|c|c|c|c|c|c|c|}
\hline & \multicolumn{2}{|c|}{ Full Sample } & \multicolumn{2}{|c|}{ UTSG } & \multicolumn{2}{|c|}{ UTM } \\
\hline & Control & Treatment & Control & Treatment & Control & Treatment \\
\hline Number of Students & 1,849 & 1,732 & 1,106 & 938 & 743 & 794 \\
\hline (i) Fraction of total & 39.97 & 37.44 & 35.82 & 30.38 & 48.34 & 51.66 \\
\hline (ii) Intended fraction & - & - & 33 & 33 & 50.00 & 50.00 \\
\hline p-value of (i) = (ii) & - & - & 0.001 & 0.002 & 0.193 & 0.193 \\
\hline Completed Exercise & 1,802 & 1,685 & 1,081 & 916 & 721 & 769 \\
\hline $\begin{array}{l}\text { Notes: The fractions in } \\
\text { ran another intervention } \\
\text { intervention are include } \\
\text { observations throughou }\end{array}$ & $\begin{array}{l}\text { whole sam } \\
\text { ddition to } \\
\text { ly in this t } \\
\text { remainde }\end{array}$ & $\begin{array}{l}\text { and at St. Ge } \\
\text { e time manag } \\
\text { le to construc } \\
\text { f the analysis. }\end{array}$ & $\begin{array}{l}\text { e (UTSG) } \\
\text { ent interve } \\
\text { e fraction }\end{array}$ & $\begin{array}{l}\text { not sum to c } \\
\text { n. Students } \\
\text { tudents in ea }\end{array}$ & $\begin{array}{l}\text { because th } \\
\text { received } \\
\text { group. We }\end{array}$ & $\begin{array}{l}\text { JTSG campus } \\
\text { other } \\
\text { op these }\end{array}$ \\
\hline
\end{tabular}


Table 2: Balancing Tests at UTSG

\begin{tabular}{|c|c|c|}
\hline & \multicolumn{2}{|c|}{ Treatment Status } \\
\hline & Control & Treatment \\
\hline Student Characteristics & $\begin{array}{c}\text { Sample Mean } \\
\text { [Standard Deviation] }\end{array}$ & $\begin{array}{c}\text { Difference } \\
\text { [Standard Error] }\end{array}$ \\
\hline \multirow[t]{2}{*}{ Male } & 0.477 & -0.016 \\
\hline & {$[0.500]$} & {$[0.023]$} \\
\hline \multirow[t]{2}{*}{ Age } & 18.639 & 0.017 \\
\hline & {$[2.070]$} & [0.092] \\
\hline \multirow[t]{2}{*}{ High School Admission Average } & 90.598 & -0.263 \\
\hline & {$[4.078]$} & {$[0.232]$} \\
\hline \multirow[t]{2}{*}{ English Mother Tongue } & 0.399 & -0.002 \\
\hline & {$[0.490]$} & {$[0.023]$} \\
\hline \multirow[t]{2}{*}{ Intends to Earn more than BA } & 0.739 & -0.021 \\
\hline & {$[0.440]$} & {$[0.020]$} \\
\hline \multirow[t]{2}{*}{ First Generation Student } & 0.226 & 0.013 \\
\hline & [0.418] & {$[0.019]$} \\
\hline \multirow[t]{2}{*}{ Expects to Earn at Least an A- Grade Average } & 0.481 & 0.016 \\
\hline & {$[0.500]$} & {$[0.022]$} \\
\hline \multirow[t]{2}{*}{ Expected Work Hours in Current Year } & 6.433 & 0.077 \\
\hline & [9.172] & {$[0.414]$} \\
\hline \multirow[t]{2}{*}{ Think about the future (1 to 7) } & 5.614 & 0.029 \\
\hline & {$[1.223]$} & {$[0.053]$} \\
\hline \multirow[t]{2}{*}{ Transition has been so far challenging ( 1 to 7 ) } & 4.571 & -0.027 \\
\hline & {$[1.616]$} & {$[0.072]$} \\
\hline \multirow[t]{2}{*}{ Tend to cram for exams (1 to 7 ) } & 4.099 & -0.011 \\
\hline & [1.558] & {$[0.068]$} \\
\hline \multirow[t]{2}{*}{ Expected Study Hours Per Week in University } & 18.588 & -0.500 \\
\hline & [12.177] & {$[0.537]$} \\
\hline \multirow[t]{2}{*}{ Study Hours Per Week in High School } & 13.665 & -0.414 \\
\hline & [11.812] & {$[0.505]$} \\
\hline \multirow[t]{2}{*}{ Time Spent Commuting to Campus (mins) } & 23.888 & 0.723 \\
\hline & [27.429] & {$[1.246]$} \\
\hline \multirow[t]{2}{*}{ International Student } & 0.520 & -0.013 \\
\hline & {$[0.500]$} & {$[0.022]$} \\
\hline \multirow[t]{2}{*}{ First-Year Student } & 0.744 & -0.010 \\
\hline & [0.437] & {$[0.020]$} \\
\hline Number of Students & \multicolumn{2}{|c|}{2,044} \\
\hline \multicolumn{3}{|c|}{$\begin{array}{l}\text { Notes: Summary statistics and differences are calculated using the full sample of students at UTSG } \\
\text { Robust standard errors are reported in brackets. }\end{array}$} \\
\hline
\end{tabular}


Table 3: Balancing Tests at UTM

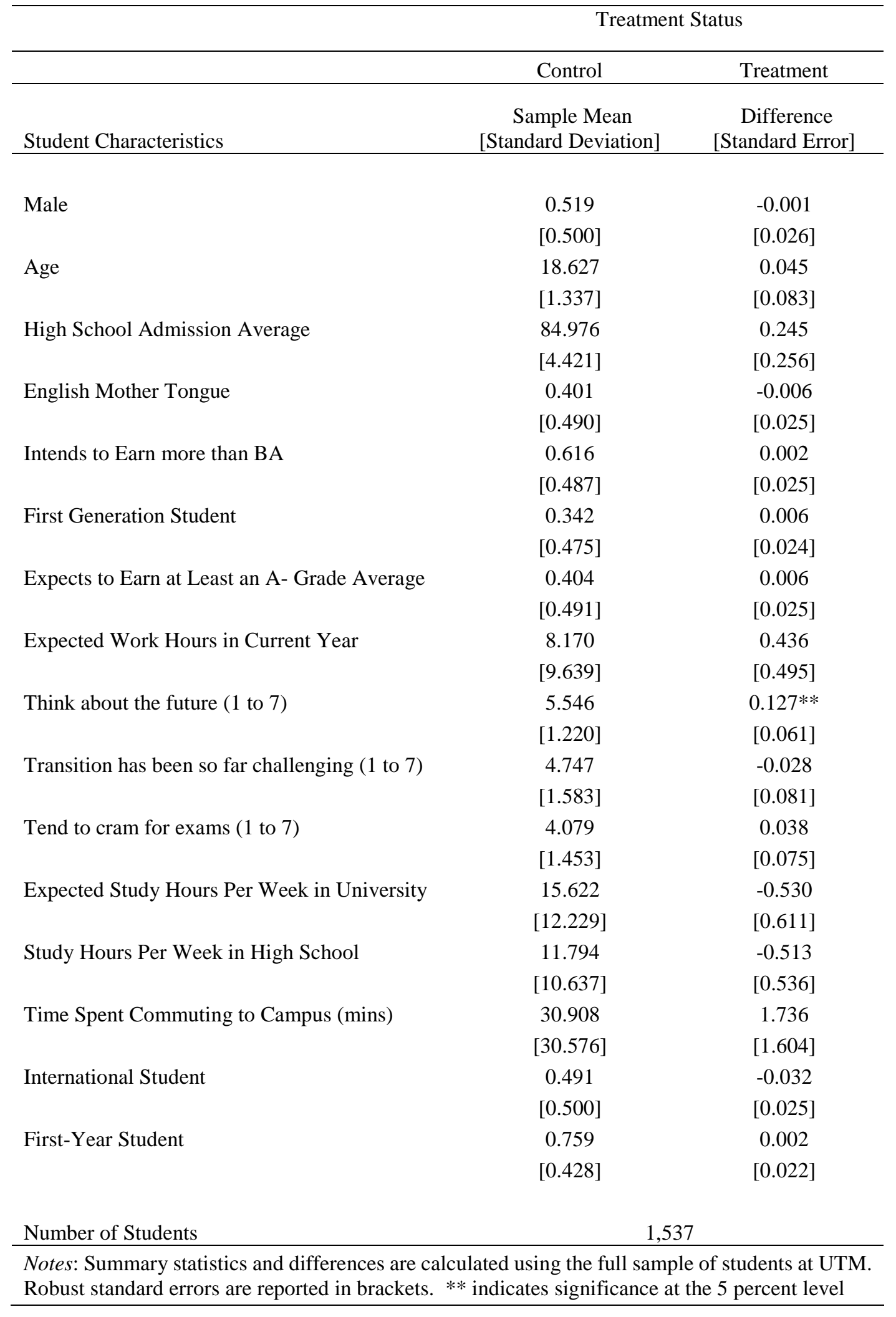


Table 4: Balancing Tests at WGU

\begin{tabular}{|c|c|c|}
\hline & \multicolumn{2}{|c|}{ Treatment Status } \\
\hline & Control & Treatment \\
\hline Student Characteristics & $\begin{array}{c}\text { Sample Mean } \\
\text { [Standard Deviation] }\end{array}$ & $\begin{array}{c}\text { Difference } \\
\text { [Standard Error] }\end{array}$ \\
\hline \multirow[t]{2}{*}{ Male } & 0.347 & 0.001 \\
\hline & {$[0.476]$} & {$[0.012]$} \\
\hline \multirow[t]{2}{*}{ Age } & 34.771 & $0.496^{* *}$ \\
\hline & [9.120] & {$[0.238]$} \\
\hline \multirow[t]{2}{*}{ Hispanic } & 0.107 & 0.001 \\
\hline & [0.309] & {$[0.008]$} \\
\hline \multirow[t]{2}{*}{ White } & $0.790^{*}$ & -0.002 \\
\hline & {$[0.408]$} & [0.011] \\
\hline \multirow[t]{2}{*}{ Black } & 0.108 & 0.005 \\
\hline & [0.311] & {$[0.008]$} \\
\hline \multirow[t]{2}{*}{ Asian } & 0.047 & -0.006 \\
\hline & {$[0.212]$} & [0.005] \\
\hline \multirow[t]{2}{*}{ Employment status=full time } & 0.752 & $0.023^{* *}$ \\
\hline & {$[0.432]$} & [0.011] \\
\hline \multirow[t]{2}{*}{ Employment status=part time } & 0.144 & -0.014 \\
\hline & [0.351] & [0.009] \\
\hline \multirow[t]{2}{*}{ Employment status=unemployed } & 0.104 & -0.008 \\
\hline & [0.305] & {$[0.008]$} \\
\hline \multirow[t]{2}{*}{ Income=less than 16, 000} & 0.070 & -0.004 \\
\hline & {$[0.255]$} & {$[0.007]$} \\
\hline \multirow[t]{2}{*}{ Income $=16,000$ to 24,999} & 0.084 & 0.002 \\
\hline & {$[0.278]$} & {$[0.007]$} \\
\hline \multirow[t]{2}{*}{ Income $=25,000$ to 34,999} & 0.114 & -0.010 \\
\hline & [0.318] & [0.008] \\
\hline \multirow[t]{2}{*}{ Income $=35,000$ to 44, 999} & 0.132 & -0.010 \\
\hline & [0.338] & [0.009] \\
\hline \multirow[t]{2}{*}{ Income $=45,000$ to 64,999} & 0.196 & $0.025^{* *}$ \\
\hline & [0.397] & [0.011] \\
\hline \multirow[t]{2}{*}{ Income $=65,000$ or more } & 0.404 & -0.004 \\
\hline & [0.491] & [0.013] \\
\hline First generation student & $\begin{array}{c}0.423 \\
{[0.494]}\end{array}$ & $\begin{array}{c}0.022^{*} \\
{[0.013]}\end{array}$ \\
\hline Number of students & \multicolumn{2}{|c|}{6,065} \\
\hline \multicolumn{3}{|c|}{$\begin{array}{l}\text { Notes: Summary statistics and differences are calculated using the full sample o } \\
\text { students at WGU. Robust standard errors are reported in brackets. ** indicates } \\
\text { significance at the } 5 \text { percent level, and * at the } 10 \text { percent level. }\end{array}$} \\
\hline
\end{tabular}


Table 5: Summary Statistics for Study Habits from Follow-Up Survey at UofT

\begin{tabular}{|c|c|c|c|c|c|c|}
\hline & \multicolumn{2}{|c|}{ Full Sample } & \multicolumn{2}{|c|}{ UTSG } & \multicolumn{2}{|c|}{ UTM } \\
\hline & Control & Treatment & Control & Treatment & Control & Treatment \\
\hline \multirow[t]{2}{*}{ Regular Week } & 15.595 & 17.083 & 16.756 & 18.525 & 13.978 & 15.483 \\
\hline & [13.135] & [12.262] & [13.885] & [12.959] & [11.842] & [11.241] \\
\hline \multirow[t]{2}{*}{ Midterms/Exams Week } & 24.779 & 24.258 & 28.142 & 28.105 & 20.108 & 19.966 \\
\hline & [17.922] & [15.253] & [18.667] & [15.766] & [15.072] & [13.434] \\
\hline Observations & 871 & 848 & 507 & 446 & 364 & 402 \\
\hline
\end{tabular}


Table 6: Associations Between Weekly Study Time and Student Grade Outcomes

(1)

(2)

(3)

(4)

Panel A: Mean Grade and GPA Across All Fall Courses

Dependent Variable: Mean Fall Grade

Mean Fall GPA

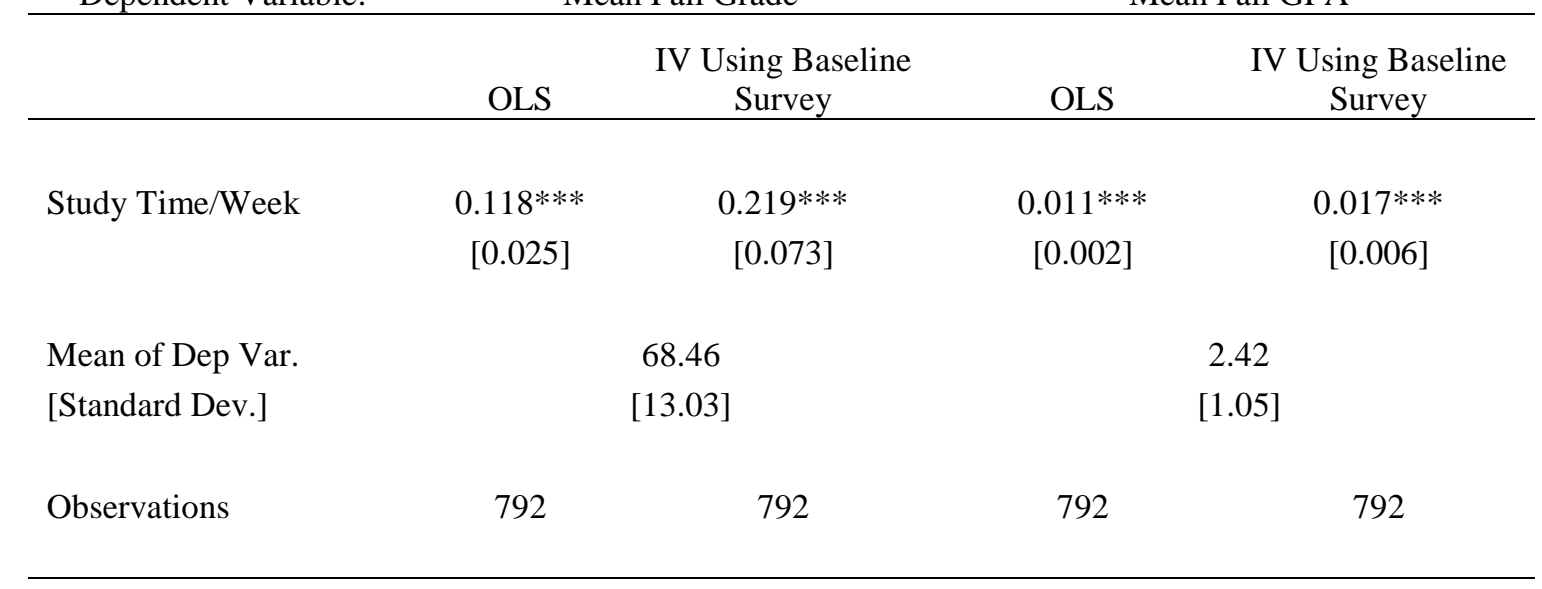

Panel B: Mean Grade Across Fall Math and Economics Courses

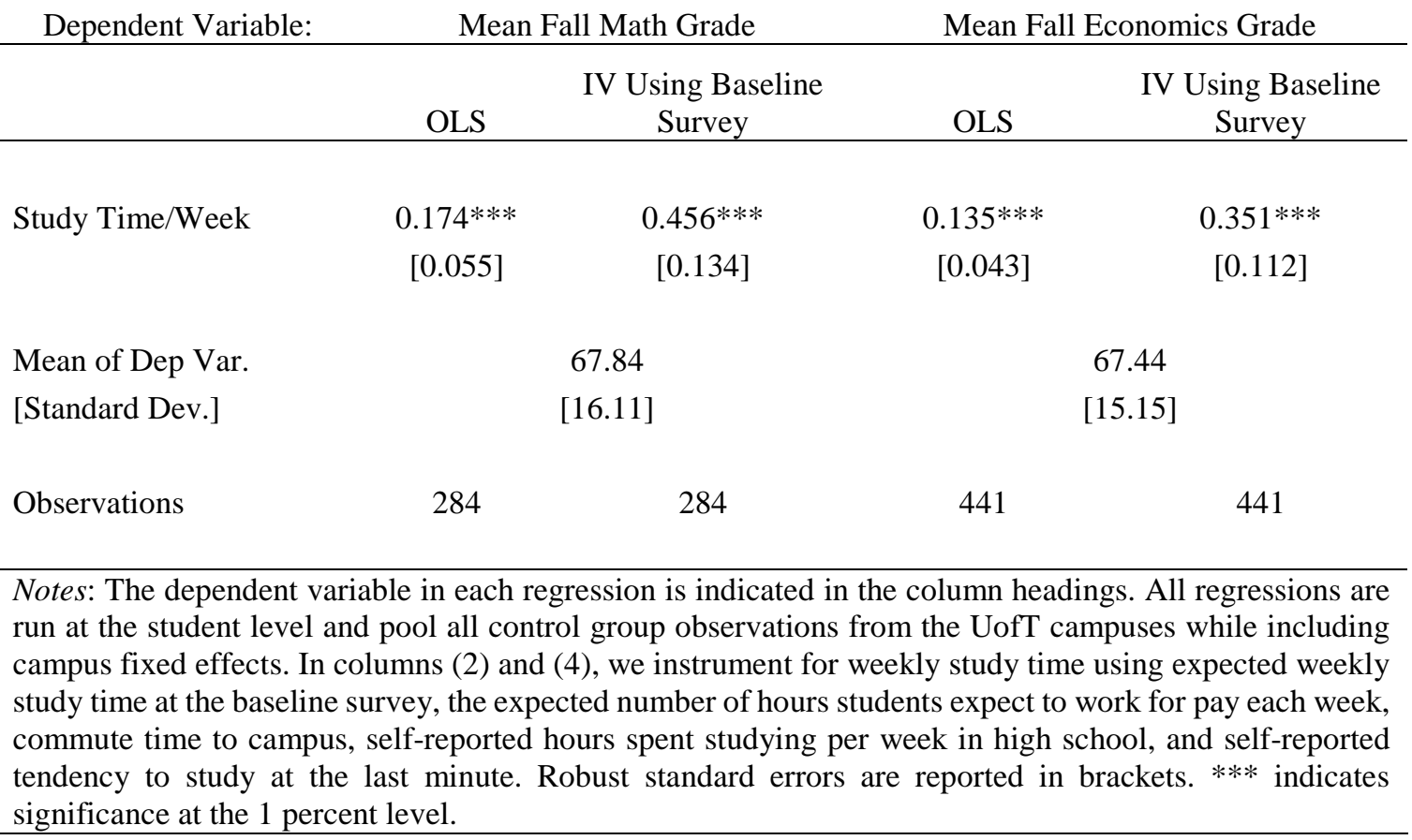


Table 7: Treatment Effects on Self-Reported Study Times at UofT

\begin{tabular}{|c|c|c|c|}
\hline$(1)$ & (2) & (3) & (4) \\
\hline Sample and & Control Mean & Treatment & Treatment \\
\hline Dependent Variable & [Standard Deviation] & Difference & Difference \\
\hline \multicolumn{4}{|l|}{ Pooled UofT Sample } \\
\hline \multirow[t]{3}{*}{ Regular Week Study } & 15.595 & $1.651^{* * *}$ & $1.691 * * *$ \\
\hline & [13.135] & [0.609] & [0.582] \\
\hline & & 1,719 & 1,628 \\
\hline \multirow[t]{3}{*}{ Exam Week Study } & 24.779 & -0.084 & 0.196 \\
\hline & [17.922] & [0.779] & {$[0.748]$} \\
\hline & & 1,714 & 1,623 \\
\hline \multicolumn{4}{|l|}{ UTSG } \\
\hline \multirow[t]{3}{*}{ Regular Week Study } & 16.756 & $1.769 * *$ & $1.618^{*}$ \\
\hline & [13.885] & {$[0.870]$} & {$[0.844]$} \\
\hline & & 953 & 873 \\
\hline \multirow[t]{3}{*}{ Exam Week Study } & 28.142 & -0.037 & 0.153 \\
\hline & [18.668] & [1.117] & [1.093] \\
\hline & & 951 & 871 \\
\hline \multicolumn{4}{|l|}{ UTM } \\
\hline \multirow[t]{3}{*}{ Regular Week Study } & 13.978 & $1.505^{*}$ & $1.633^{* *}$ \\
\hline & [11.842] & {$[0.836]$} & {$[0.796]$} \\
\hline & & 766 & 755 \\
\hline \multirow[t]{3}{*}{ Exam Week Study } & 20.108 & -0.142 & 0.282 \\
\hline & [15.702] & [1.063] & [1.001] \\
\hline & & 763 & 752 \\
\hline Controls? & & No & Yes \\
\hline \multicolumn{4}{|c|}{$\begin{array}{l}\text { Notes: The dependent variable in each regression and the sample used are indicated in the rows } \\
\text { of column (1). The unit of observation is a student. Control variables include student age, self- } \\
\text { reported study hours per week during high school, expected hours per week studying this } \\
\text { semester, expected paid-work hours per week, tendency to think about future goals, tendency } \\
\text { to study at the last minute, difficulty transitioning to university, commuting time (in minutes) } \\
\text { to campus, and indicator variables for first-year status, international student status, first- } \\
\text { generation status, gender, English mother-tongue status, a self-reported desire to earn more } \\
\text { than an undergraduate degree, and a self-reported expectation to earn an A- average grade or } \\
\text { greater. Robust standard errors are reported in brackets in columns (3) to (4). The number of } \\
\text { observations used in each regression appears below the standard errors. }{ }^{* * *} \text { indicates } \\
\text { significance at the } 1 \text { percent level; ** indicates significance at the } 5 \text { percent level; and * } \\
\text { indicates significance at the } 10 \text { percent level. }\end{array}$} \\
\hline
\end{tabular}


Table 8: Treatment Effect on Click Data at WGU

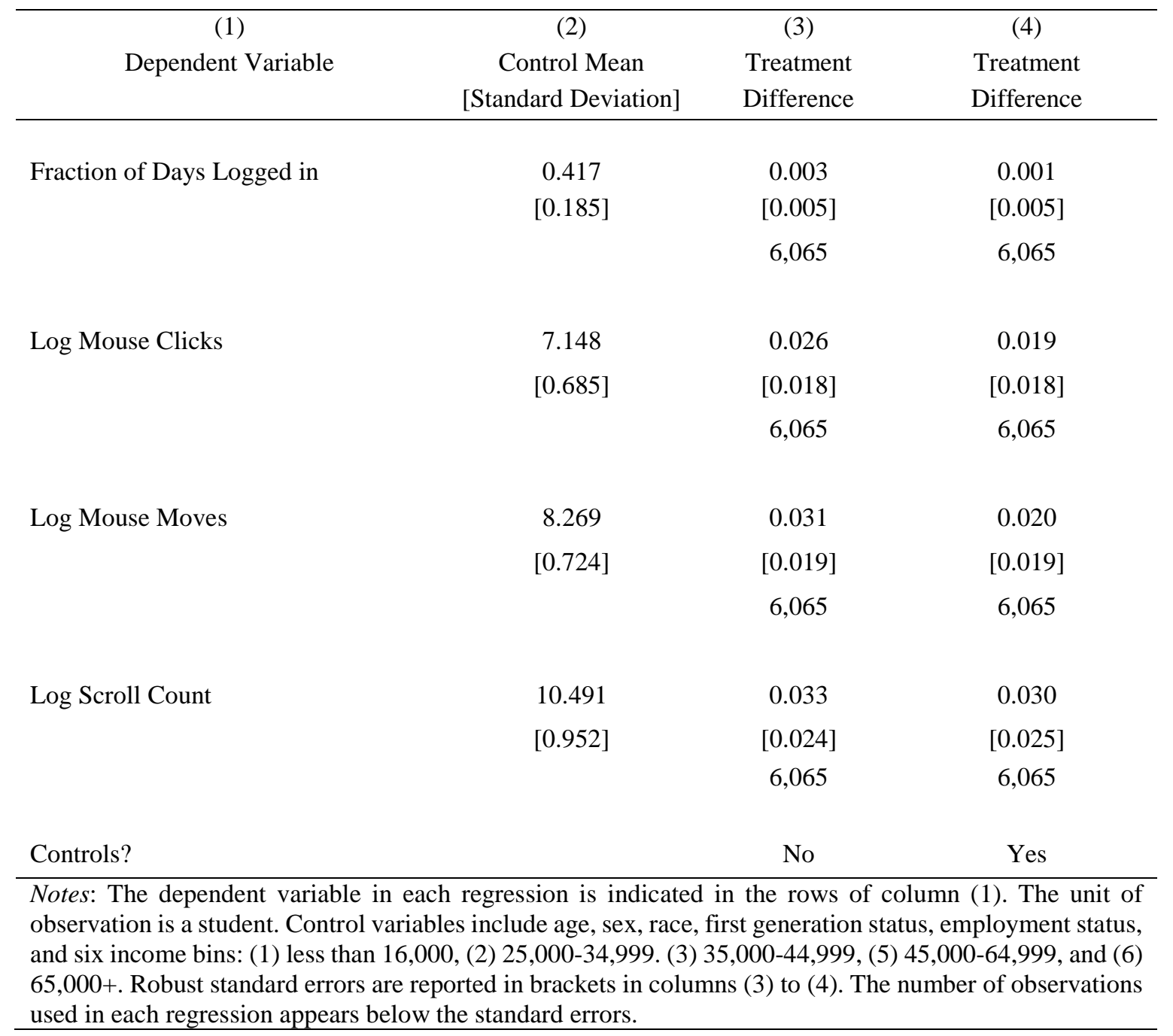


Table 9: Treatment Effects on Credit Accumulation and Retention

\begin{tabular}{|c|c|c|c|}
\hline $\begin{array}{l}\text { (1) } \\
\text { Dependent Variable and } \\
\text { Sample }\end{array}$ & $\begin{array}{c}(2) \\
\text { Control Mean } \\
\text { [Standard Deviation] }\end{array}$ & $\begin{array}{c}(3) \\
\text { Treatment } \\
\text { Difference } \\
\end{array}$ & $\begin{array}{c}\text { (4) } \\
\text { Treatment } \\
\text { Difference } \\
\end{array}$ \\
\hline \multicolumn{4}{|l|}{ Credits Attempted } \\
\hline UTSG & $\begin{array}{c}3.799 \\
{[1.243]}\end{array}$ & $\begin{array}{c}0.025 \\
{[0.058]} \\
1,860\end{array}$ & $\begin{array}{c}0.026 \\
{[0.056]} \\
1,860\end{array}$ \\
\hline UTM & $\begin{array}{c}3.611 \\
{[1.370]}\end{array}$ & $\begin{array}{c}0.030 \\
{[0.070]} \\
1,484\end{array}$ & $\begin{array}{c}0.035 \\
{[0.068]} \\
1,484\end{array}$ \\
\hline WGU & $\begin{array}{l}16.987 \\
{[9.107]}\end{array}$ & $\begin{array}{c}0.225 \\
{[0.234]} \\
6,064\end{array}$ & $\begin{array}{c}0.226 \\
{[0.228]} \\
6,064\end{array}$ \\
\hline \multicolumn{4}{|l|}{ Credits Earned } \\
\hline UTSG & $\begin{array}{c}3.479 \\
{[1.425]}\end{array}$ & $\begin{array}{c}0.011 \\
{[0.065]} \\
1,860\end{array}$ & $\begin{array}{c}0.010 \\
{[0.064]} \\
1,860\end{array}$ \\
\hline UTM & $\begin{array}{c}3.193 \\
{[1.557]}\end{array}$ & $\begin{array}{c}-0.119 \\
{[0.080]} \\
1,484\end{array}$ & $\begin{array}{c}-0.114 \\
{[0.078]} \\
1,484\end{array}$ \\
\hline WGU & $\begin{array}{c}14.434 \\
{[10.553]}\end{array}$ & $\begin{array}{c}0.161 \\
{[0.273]} \\
6,064\end{array}$ & $\begin{array}{c}0.144 \\
{[0.267]} \\
6,064\end{array}$ \\
\hline \multicolumn{4}{|l|}{ Retention } \\
\hline UTSG & $\begin{array}{c}0.997 \\
{[0.054]}\end{array}$ & $\begin{array}{c}0.002 \\
{[0.002]} \\
1,860\end{array}$ & $\begin{array}{c}0.002 \\
{[0.002]} \\
1,860\end{array}$ \\
\hline UTM & $\begin{array}{c}0.999 \\
{[0.037]}\end{array}$ & $\begin{array}{c}0.001 \\
{[0.001]} \\
1,484\end{array}$ & $\begin{array}{c}0.001 \\
{[0.001]} \\
1,484\end{array}$ \\
\hline WGU & $\begin{array}{c}0.891 \\
{[0.312]}\end{array}$ & $\begin{array}{c}-0.014^{*} \\
{[0.008]} \\
6,064\end{array}$ & $\begin{array}{c}-0.016^{*} \\
{[0.008]} \\
6,064\end{array}$ \\
\hline Controls? & & No & Yes \\
\hline $\begin{array}{l}\text { Notes: The dependent var } \\
\text { rows of column (1). The u } \\
\text { samples are described in } \\
\text { are described in the notes } \\
\text { columns (3) to (4). The nu } \\
\text { standard errors. * indicate }\end{array}$ & $\begin{array}{l}\text { le in each regression a } \\
\text { of observation is a stuc } \\
\text { notes of Table } 7 \text {. Col } \\
\text { f Table } 8 \text {. Robust stan } \\
\text { ber of observations use } \\
\text { ignificance at the } 10 \mathrm{p}\end{array}$ & $\begin{array}{l}\text { Ce sample us } \\
\text { Control vari } \\
\text { variables us } \\
\text { errors are } r \\
\text { each regress } \\
\text { t level. }\end{array}$ & $\begin{array}{l}\text { ndicated in the } \\
\text { sed in the UofT } \\
\text { WGU sample } \\
\text { in brackets in } \\
\text { ears below the }\end{array}$ \\
\hline
\end{tabular}




\section{Table 10: Treatment Effects on Grades at UofT and Days to Completion at WGU}

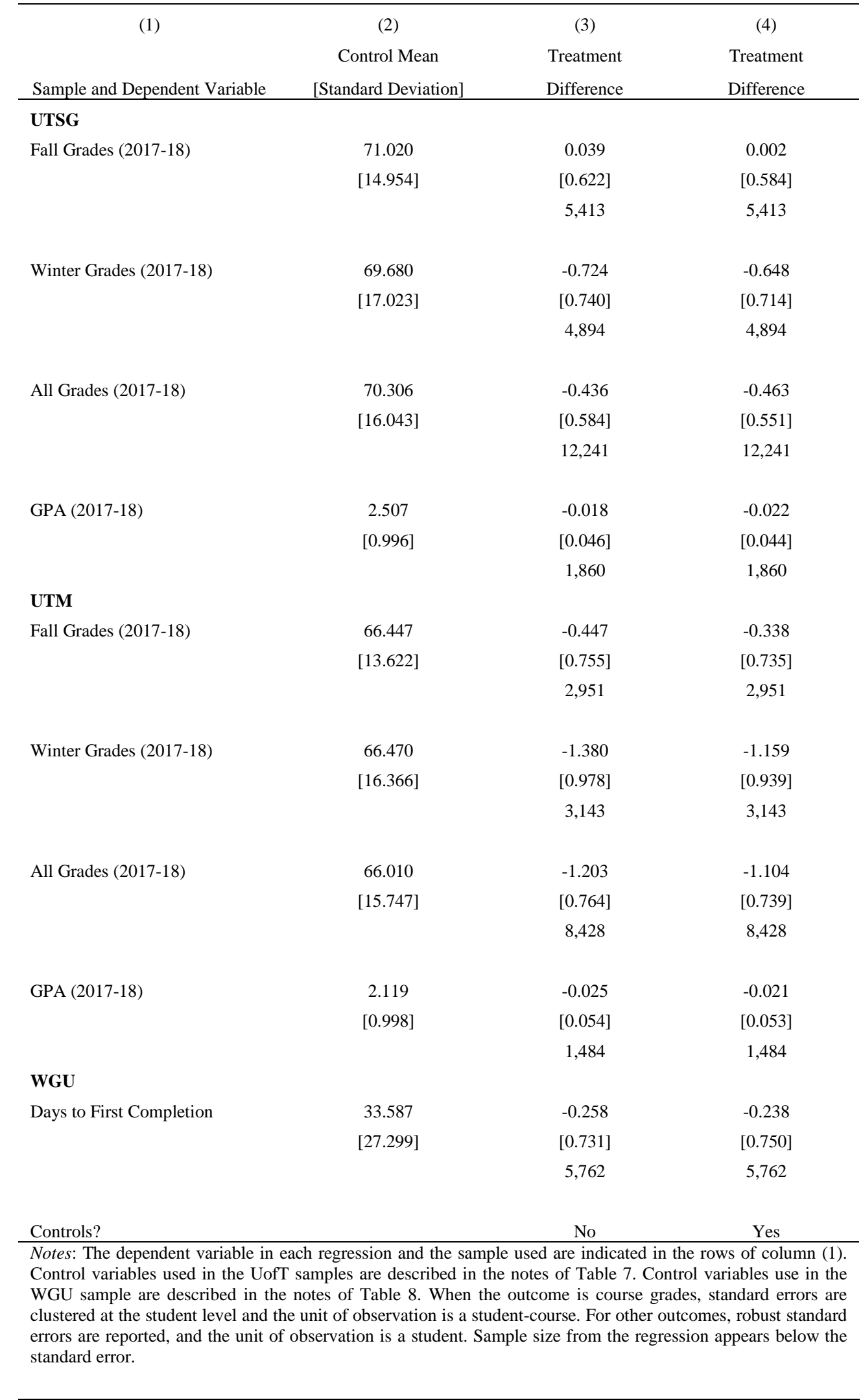


Table 11: Treatment Effects on Course Grades by Student Subgroup at UTSG

\begin{tabular}{|c|c|c|c|c|}
\hline $\begin{array}{c}\text { (1) } \\
\text { Subgroup }\end{array}$ & $\begin{array}{c}\text { (2) } \\
\text { Observations }\end{array}$ & $\begin{array}{c}\text { (3) } \\
\text { Control Mean } \\
\text { [Standard Deviation] }\end{array}$ & $\begin{array}{c}(4) \\
\text { Treatment } \\
\text { Difference }\end{array}$ & $\begin{array}{c}\text { (5) } \\
\text { Treatment } \\
\text { Difference }\end{array}$ \\
\hline Male & 5,799 & $\begin{array}{c}70.231 \\
{[16.398]}\end{array}$ & $\begin{array}{c}-0.313 \\
{[0.916]}\end{array}$ & $\begin{array}{l}-0.384 \\
{[0.862]}\end{array}$ \\
\hline Female & 6,442 & $\begin{array}{c}70.377 \\
{[15.704]}\end{array}$ & $\begin{array}{c}-0.547 \\
{[0.745]}\end{array}$ & $\begin{array}{c}-0.574 \\
{[0.692]}\end{array}$ \\
\hline Age $>=20$ & 1,812 & $\begin{array}{c}69.677 \\
{[17.671]}\end{array}$ & $\begin{array}{l}-1.668 \\
{[1.886]}\end{array}$ & $\begin{array}{l}-1.784 \\
{[1.809]}\end{array}$ \\
\hline Age $<20$ & 10,429 & $\begin{array}{c}70.425 \\
{[15.715]}\end{array}$ & $\begin{array}{l}-0.264 \\
{[0.604]}\end{array}$ & $\begin{array}{l}-0.042 \\
{[0.564]}\end{array}$ \\
\hline International Student & 6,427 & $\begin{array}{c}69.376 \\
{[16.105]}\end{array}$ & $\begin{array}{l}-0.080 \\
{[0.812]}\end{array}$ & $\begin{array}{c}-0.365 \\
{[0.746]}\end{array}$ \\
\hline Domestic Student & 5,814 & $\begin{array}{c}71.390 \\
{[15.904]}\end{array}$ & $\begin{array}{c}-0.924 \\
{[0.833]}\end{array}$ & $\begin{array}{c}-0.824 \\
{[0.787]}\end{array}$ \\
\hline Expected Weekly Work Hours $>=8$ & 3,724 & $\begin{array}{c}68.051 \\
{[16.859]}\end{array}$ & $\begin{array}{l}-0.573 \\
{[1.059]}\end{array}$ & $\begin{array}{c}-0.691 \\
{[0.982]}\end{array}$ \\
\hline Expected Weekly Work Hours $<8$ & 8,517 & $\begin{array}{c}71.367 \\
{[15.533]}\end{array}$ & $\begin{array}{c}-0.541 \\
{[0.689]}\end{array}$ & $\begin{array}{l}-0.411 \\
{[0.659]}\end{array}$ \\
\hline First-Generation Student & 2,649 & $\begin{array}{c}67.421 \\
{[16.401]}\end{array}$ & $\begin{array}{l}-0.015 \\
{[1.293]}\end{array}$ & $\begin{array}{l}-0.489 \\
{[1.262]}\end{array}$ \\
\hline Not First-Generation Student & 9,592 & $\begin{array}{c}71.056 \\
{[15.864]}\end{array}$ & $\begin{array}{l}-0.455 \\
{[0.648]}\end{array}$ & $\begin{array}{l}-0.403 \\
{[0.614]}\end{array}$ \\
\hline First-Year Student & 9,444 & $\begin{array}{c}71.264 \\
{[15.326]}\end{array}$ & $\begin{array}{c}-0.564 \\
{[0.614]}\end{array}$ & $\begin{array}{l}-0.340 \\
{[0.590]}\end{array}$ \\
\hline Not First-Year Student & 2,797 & $\begin{array}{c}67.123 \\
{[17.864]}\end{array}$ & $\begin{array}{l}-0.109 \\
{[1.445]}\end{array}$ & $\begin{array}{l}-0.609 \\
{[1.355]}\end{array}$ \\
\hline Controls? & & & No & Yes \\
\hline $\begin{array}{l}\text { Notes: The dependent variable in e } \\
\text { notes of Table } 7 \text {. The subsample o } \\
\text { (1). The unit of observation in eacl } \\
\text { student level. }\end{array}$ & $\begin{array}{l}\mathrm{h} \text { regression is } \\
\text { tudents used } \mathrm{f} \\
\text { egression is a }\end{array}$ & $\begin{array}{l}\text { ourse grades. Control } \\
\text { each regression is ind } \\
\text { dent-course and stand }\end{array}$ & $\begin{array}{l}\text { riables are } \\
\text { ted by the } \\
\text { errors are }\end{array}$ & $\begin{array}{l}\text { cribed in the } \\
\text { s of column } \\
\text { stered at the }\end{array}$ \\
\hline
\end{tabular}


Table 12: Treatment Effects on Course Grades by Student Subgroup at UTM

\begin{tabular}{|c|c|c|c|c|}
\hline $\begin{array}{c}\text { (1) } \\
\text { Subgroup }\end{array}$ & $\begin{array}{c}\text { (2) } \\
\text { Observations }\end{array}$ & $\begin{array}{c}\text { (3) } \\
\text { Control Mean } \\
\text { [Standard Deviation] }\end{array}$ & $\begin{array}{c}\text { (4) } \\
\text { Treatment } \\
\text { Difference } \\
\end{array}$ & $\begin{array}{c}\text { (5) } \\
\text { Treatment } \\
\text { Difference }\end{array}$ \\
\hline Male & 4,270 & $\begin{array}{c}65.030 \\
{[16.353]}\end{array}$ & $\begin{array}{c}-2.390 * * \\
{[1.153]}\end{array}$ & $\begin{array}{l}-1.902^{*} \\
{[1.095]}\end{array}$ \\
\hline Female & 4,158 & $\begin{array}{c}67.009 \\
{[15.044]}\end{array}$ & $\begin{array}{c}0.040 \\
{[0.971]}\end{array}$ & $\begin{array}{c}-0.083 \\
{[0.953]}\end{array}$ \\
\hline Age $>=20$ & 1,398 & $\begin{array}{c}64.571 \\
{[16.806]}\end{array}$ & $\begin{array}{l}-1.171 \\
{[2.012]}\end{array}$ & $\begin{array}{l}-1.154 \\
{[2.006]}\end{array}$ \\
\hline Age $<20$ & 7,030 & $\begin{array}{c}66.300 \\
{[15.512]}\end{array}$ & $\begin{array}{c}-1.217 \\
{[0.823]}\end{array}$ & $\begin{array}{c}-0.921 \\
{[0.783]}\end{array}$ \\
\hline International Student & 3,744 & $\begin{array}{c}64.969 \\
{[15.941]}\end{array}$ & $\begin{array}{l}-1.101 \\
{[1.137]}\end{array}$ & $\begin{array}{c}-1.293 \\
{[1.113]}\end{array}$ \\
\hline Domestic Student & 4,684 & $\begin{array}{c}66.902 \\
{[15.528]}\end{array}$ & $\begin{array}{l}-1.391 \\
{[1.029]}\end{array}$ & $\begin{array}{c}-0.678 \\
{[0.988]}\end{array}$ \\
\hline Expected Weekly Work Hours $>=8$ & 3,579 & $\begin{array}{c}65.378 \\
{[16.024]}\end{array}$ & $\begin{array}{l}-1.939 \\
{[1.198]}\end{array}$ & $\begin{array}{l}-1.918^{*} \\
{[1.158]}\end{array}$ \\
\hline Expected Weekly Work Hours $<8$ & 4,849 & $\begin{array}{c}66.474 \\
{[15.529]}\end{array}$ & $\begin{array}{l}-0.650 \\
{[0.989]}\end{array}$ & $\begin{array}{c}-0.680 \\
{[0.947]}\end{array}$ \\
\hline First-Generation Student & 2,862 & $\begin{array}{c}64.058 \\
{[16.164]}\end{array}$ & $\begin{array}{l}-1.144 \\
{[1.316]}\end{array}$ & $\begin{array}{l}-0.806 \\
{[1.278]}\end{array}$ \\
\hline Not First-Generation Student & 5,566 & $\begin{array}{c}66.996 \\
{[15.442]}\end{array}$ & $\begin{array}{l}-1.199 \\
{[0.932]}\end{array}$ & $\begin{array}{l}-1.125 \\
{[0.905]}\end{array}$ \\
\hline First-Year Student & 6,303 & $\begin{array}{c}66.730 \\
{[15.147]}\end{array}$ & $\begin{array}{l}-0.522 \\
{[0.788]}\end{array}$ & $\begin{array}{l}-0.294 \\
{[0.774]}\end{array}$ \\
\hline Not First-Year Student & 2,125 & $\begin{array}{c}63.898 \\
{[17.223]}\end{array}$ & $\begin{array}{l}-3.291 * \\
{[1.865]}\end{array}$ & $\begin{array}{c}-2.764 \\
{[1.799]}\end{array}$ \\
\hline $\begin{array}{l}\text { Controls? } \\
\text { Notes: The dependent variable in ea } \\
\text { notes of Table } 7 \text {. The subsample of } \\
\text { (1). The unit of observation in each } \\
\text { student level. ** indicates significan } \\
\text { level. }\end{array}$ & $\begin{array}{l}\mathrm{h} \text { regression is } \\
\text { tudents used fo } \\
\text { egression is a st } \\
\text { at the } 5 \text { perce }\end{array}$ & $\begin{array}{l}\text { ourse grades. Control v } \\
\text { each regression is indi } \\
\text { dent-course and standa } \\
\text { level; and * indicates }\end{array}$ & $\begin{array}{l}\text { No } \\
\text { ables are d } \\
\text { ed by the rc } \\
\text { errors are c } \\
\text { aificance at }\end{array}$ & $\begin{array}{l}\text { Yes } \\
\text { cribed in the } \\
\text { s of column } \\
\text { stered at the } \\
\text { e } 10 \text { percent }\end{array}$ \\
\hline
\end{tabular}


Table 13: Treatment Effects on Earned Credits at WGU by Student Subgroup

\begin{tabular}{|c|c|c|c|c|}
\hline (1) & (2) & (3) & (4) & (5) \\
\hline \multirow[t]{2}{*}{ Subgroup } & Observations & Control Mean & Treatment & Treatment \\
\hline & & [Standard Deviation] & Difference & Difference \\
\hline \multirow[t]{2}{*}{ Male } & 2110 & 15.130 & 0.083 & 0.128 \\
\hline & & [12.130] & {$[0.525]$} & {$[0.515]$} \\
\hline \multirow[t]{2}{*}{ Female } & 3955 & 14.063 & 0.228 & 0.200 \\
\hline & & [9.592] & {$[0.311]$} & [0.303] \\
\hline \multirow[t]{2}{*}{ Age $>=30$} & 3820 & 14.644 & 0.423 & 0.330 \\
\hline & & {$[10.535]$} & {$[0.351]$} & {$[0.341]$} \\
\hline \multirow[t]{2}{*}{ Age $<30$} & 2245 & 14.089 & -0.329 & -0.199 \\
\hline & & {$[10.578]$} & {$[0.433]$} & {$[0.423]$} \\
\hline \multirow[t]{2}{*}{ Black } & 670 & 11.172 & $-1.250^{*}$ & -0.788 \\
\hline & & [10.627] & {$[0.760]$} & [0.691] \\
\hline \multirow[t]{2}{*}{ White } & 4781 & 15.060 & 0.311 & 0.259 \\
\hline & & {$[10.715]$} & {$[0.312]$} & {$[0.307]$} \\
\hline \multirow[t]{2}{*}{ Hispanic } & 651 & 12.339 & 0.652 & 0.469 \\
\hline & & [7.499] & {$[0.657]$} & {$[0.677]$} \\
\hline \multirow[t]{2}{*}{ Employed full time } & 4465 & 13.998 & 0.202 & 0.281 \\
\hline & & {$[9.740]$} & {$[0.292]$} & {$[0.289]$} \\
\hline \multirow[t]{2}{*}{ Employed part time } & 801 & 15.216 & -0.360 & -0.348 \\
\hline & & {$[9.740]$} & {$[0.292]$} & [0.289] \\
\hline \multirow[t]{2}{*}{ Not Employed } & 580 & 14.879 & -0.037 & -0.055 \\
\hline & & [10.325] & {$[0.769]$} & {$[0.771]$} \\
\hline \multirow[t]{2}{*}{ First generation student } & 2631 & 13.679 & 0.306 & 0.365 \\
\hline & & [9.708] & {$[0.388]$} & {$[0.374]$} \\
\hline \multirow[t]{2}{*}{ Household income below 45, 000} & 1838 & 13.005 & 0.322 & 0.524 \\
\hline & & {$[10.875]$} & {$[0.501]$} & {$[0.463]$} \\
\hline \multirow[t]{2}{*}{ Household income above 45, 000} & 4227 & 15.082 & 0.044 & 0.001 \\
\hline & & [10.341] & {$[0.325]$} & $0.325]$ \\
\hline \multicolumn{2}{|l|}{ Controls? } & & No & Yes \\
\hline \multicolumn{5}{|c|}{$\begin{array}{l}\text { Notes: The dependent variable in each regression is earned credits. Control variables are described in the notes o } \\
\text { Table } 8 \text {. The subsample of students used for each regression is indicated by the rows of column (1). The unit o } \\
\text { observation in each regression is a student and robust standard errors appear in brackets. * indicates significance } \\
\text { at the } 10 \text { percent level. }\end{array}$} \\
\hline
\end{tabular}




\section{Figures}

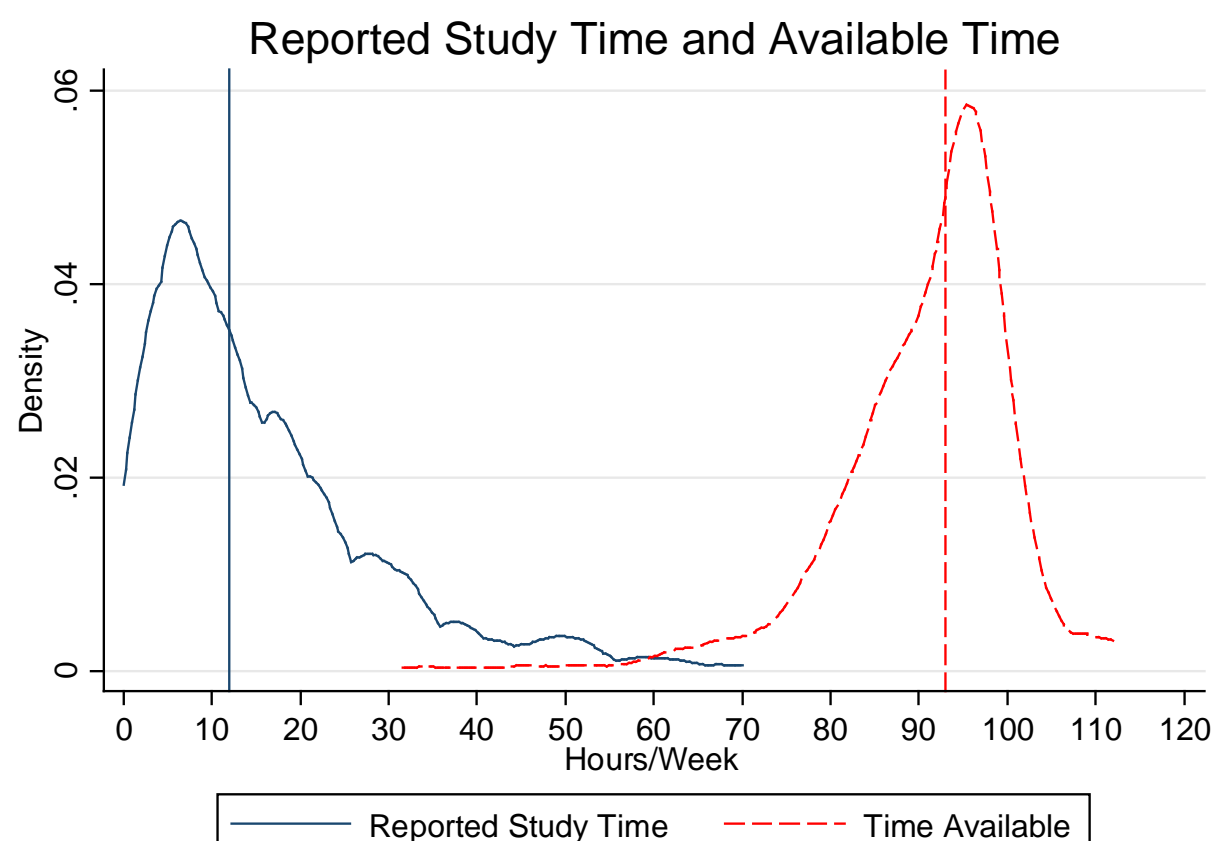

Figure 1: Student Time Use

Notes: In this figure, time available is constructed as 168 (the number of hours in a week) minus 56 hours per week for sleeping (8 hours * 7 days), students' self-reported expectation for the number of hours they will work for pay per week, students' self-reported commuting time to and from campus each week (in hours), and the time (in hours) spent in class each week (for each class, we assume three hours per week). Reported study time is gathered from student responses to a follow-up survey at the end of first semester and represents the number of hours students report having studied during a regular week in first semester. The vertical lines represent the median of each outcome. The sample used to construct the figure consists of control group students across both campuses of UofT who answered the followup survey. 


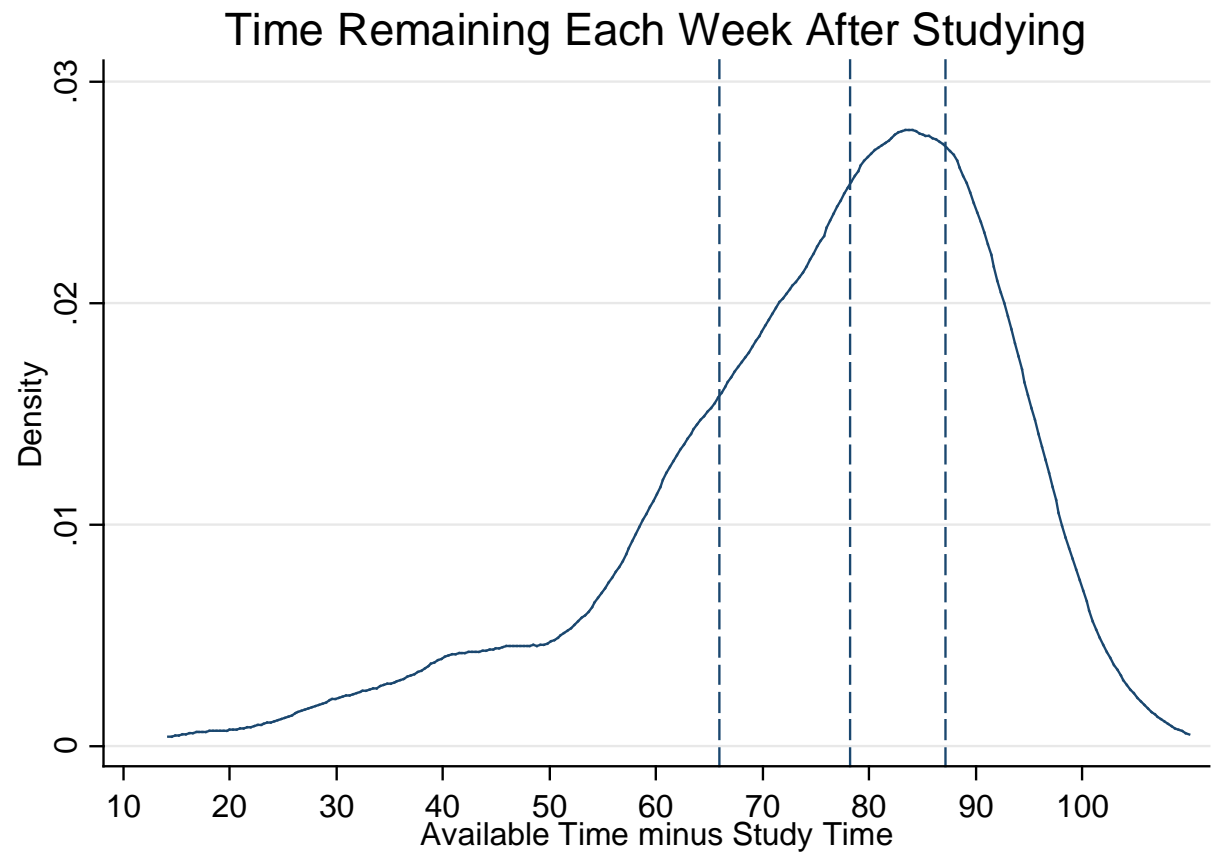

Figure 2: Student Time Remaining After Studying

Notes: This figure presents the density of time remaining after subtracting students' self-reported study time from their available time. The notes of Figure 1 provided details pertaining to the construction of available time. From left to right, the vertical lines represent the $25^{\text {th }}, 50^{\text {th }}$, and $75^{\text {th }}$, percentiles of time remaining, respectively. The sample used to construct the figure consists of control group students across both campuses of UofT who answered the follow-up survey. 


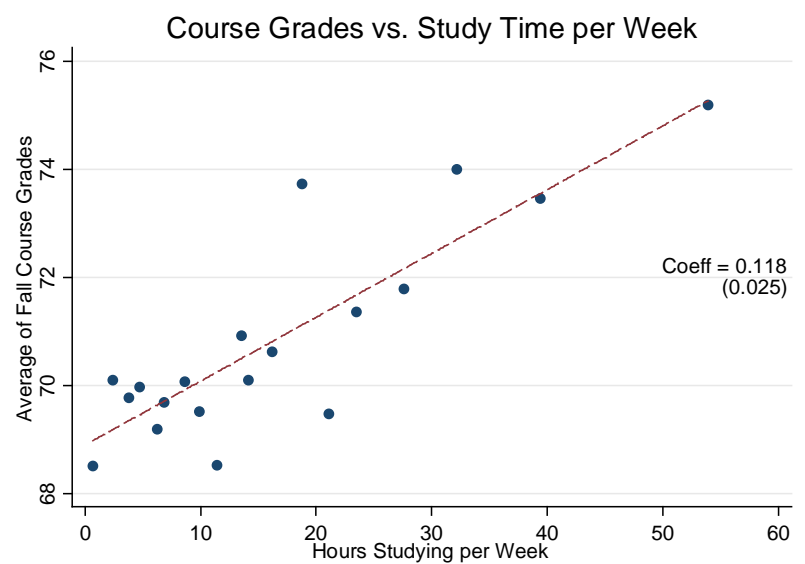

(a): Average of Fall Course Grades
Fall GPA vs. Study Time per Week

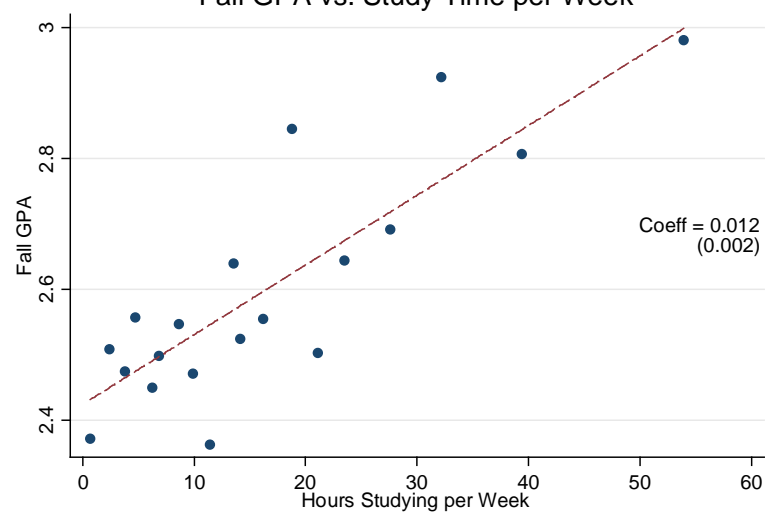

(b): Fall GPA

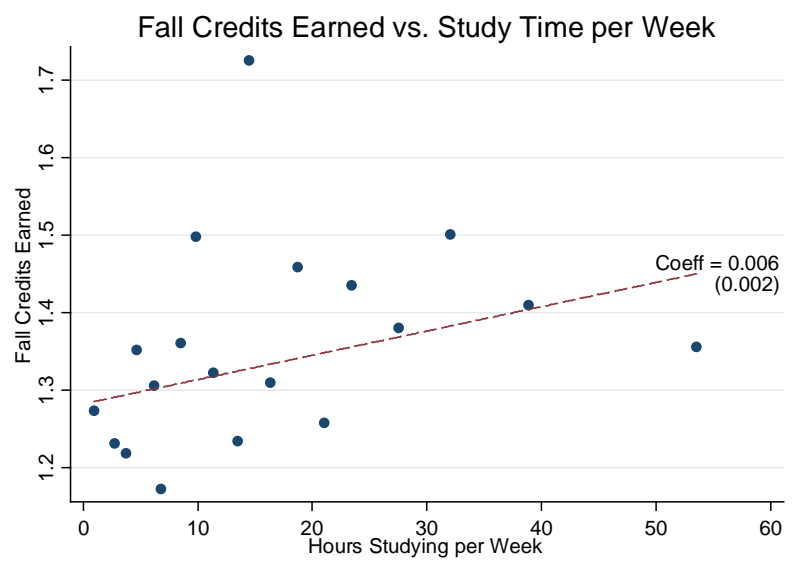

(c): Credits Earned in Fall Semester

\section{Figure 3: Relationships between Fall Semester Study Time and Academic Outcomes at UofT}

Notes: This figure presents estimated associations between the number of hours students self-report studying during a regular week in the fall semester and various academic outcomes in that semester. In panels (a), (b), and (c), respectively, the outcomes are average grade across all fall semester courses, grade-point average (GPA) across all fall semester courses, and the number of credits earned during the fall semester. The sample in each panel is restricted to students in the control group across both campuses of UofT. We construct each panel by first grouping students into 20 equally-sized (vingtile) bins of the study time distribution and then calculating the mean study time and outcome within each bin. The blue circles in each panel represent these means, while the red dashed lines represent the associated linear relationships, estimated on the underlying student-level data. Each regression controls for campus fixed effects. 


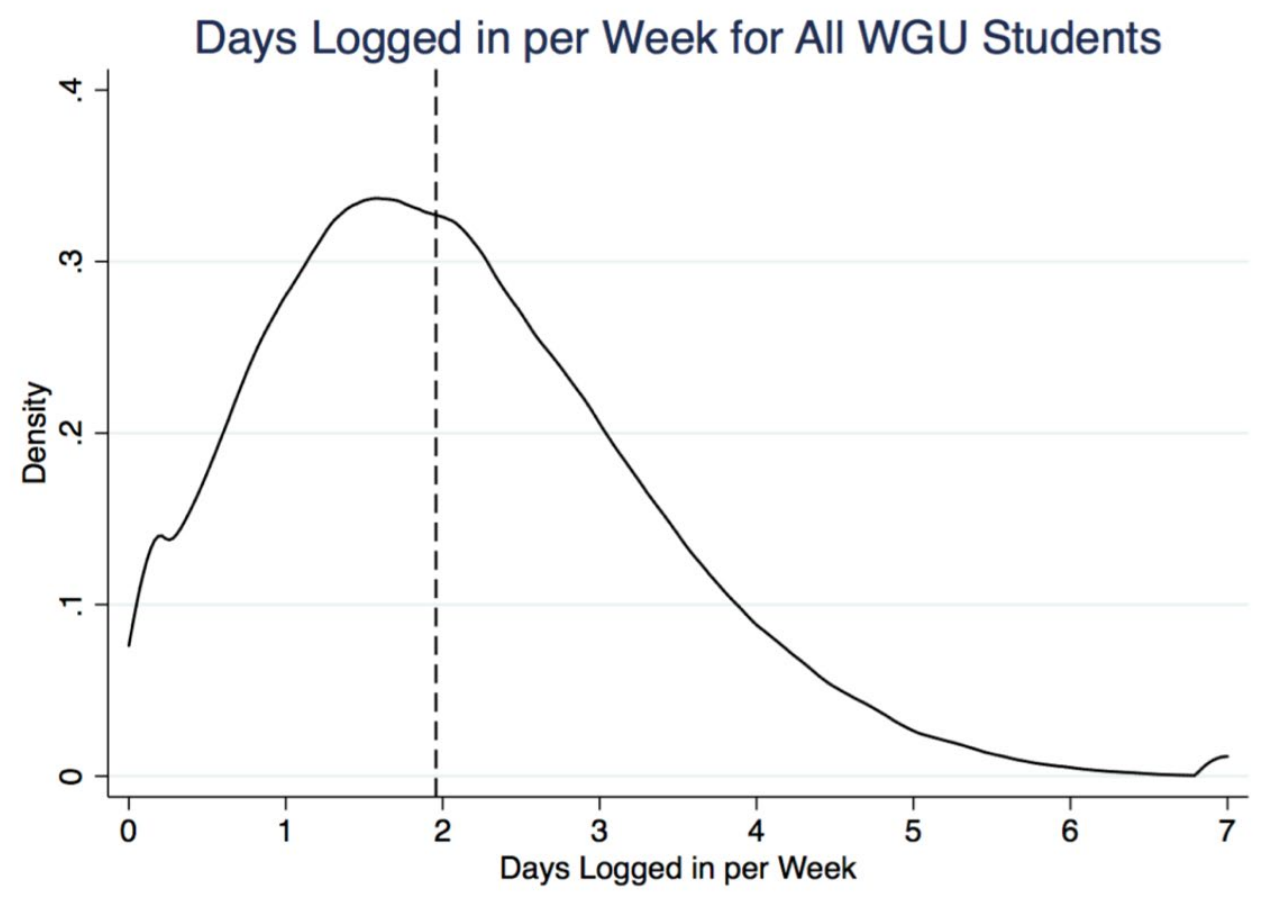

Figure 4: Days Logged in Per Week

Notes: This figure shows the distribution of the average number of days a student logs into WGU's online portal per week. The data used is for all WGU students from January 1, 2015 to July 23, 2018. The vertical line represents the median of the average number of days per week a student logs in. 


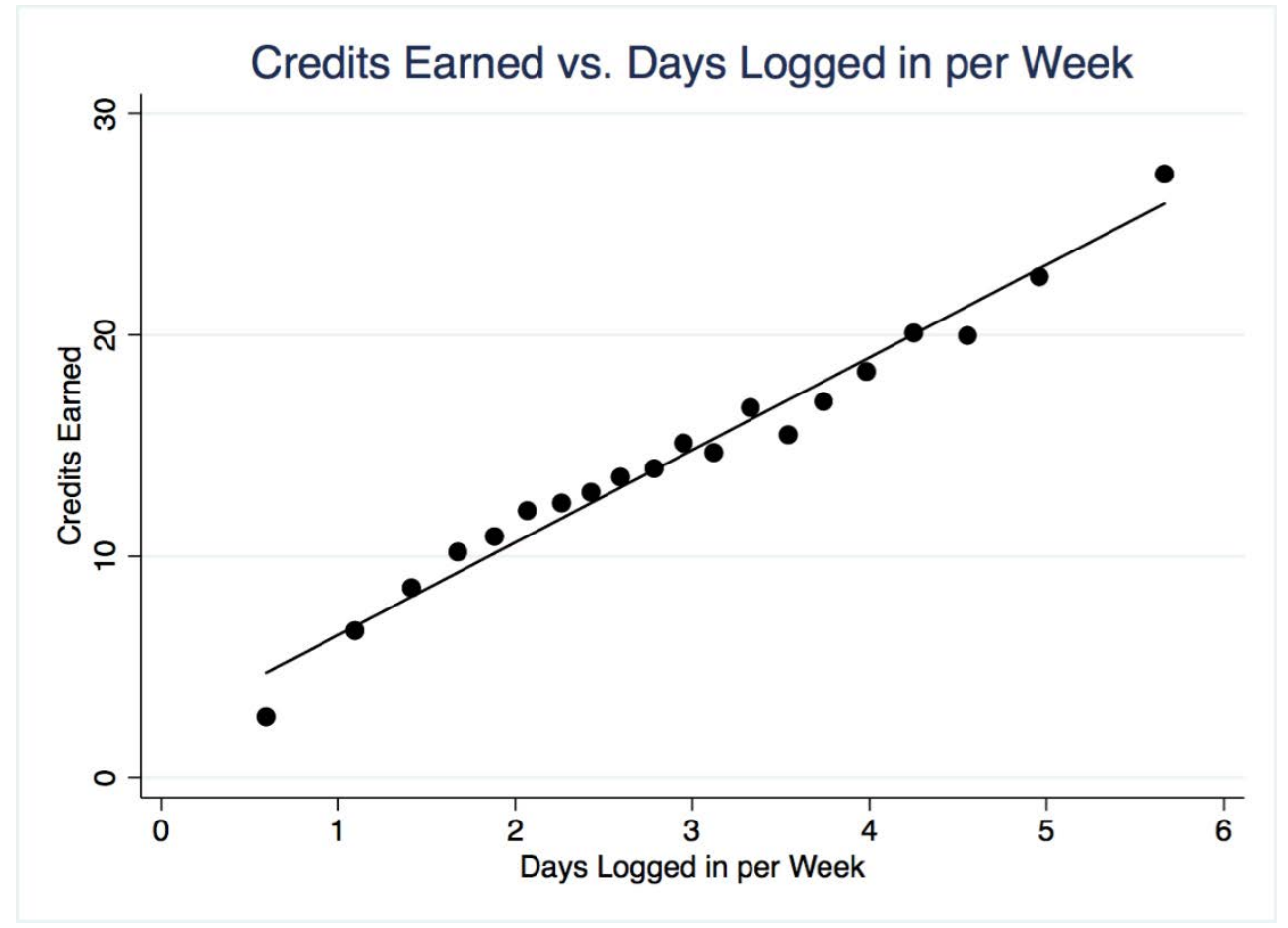

Figure 5: Relationship between Days Logged in and Credits Earned at WGU

Notes: This figure presents estimated association between the days per week students log in to the WGU web portal and credits accumulated during the semester. The sample is restricted to students in the control group at WGU. We construct this figure by first grouping students into 20 equally-sized (vingtile) bins in the distribution of the mean number of days logged in per week and then calculating the mean number of credits earned within each bin. The plotted circles represent these means, while line represents the associated linear relationship, estimated on the underlying student-level data. 


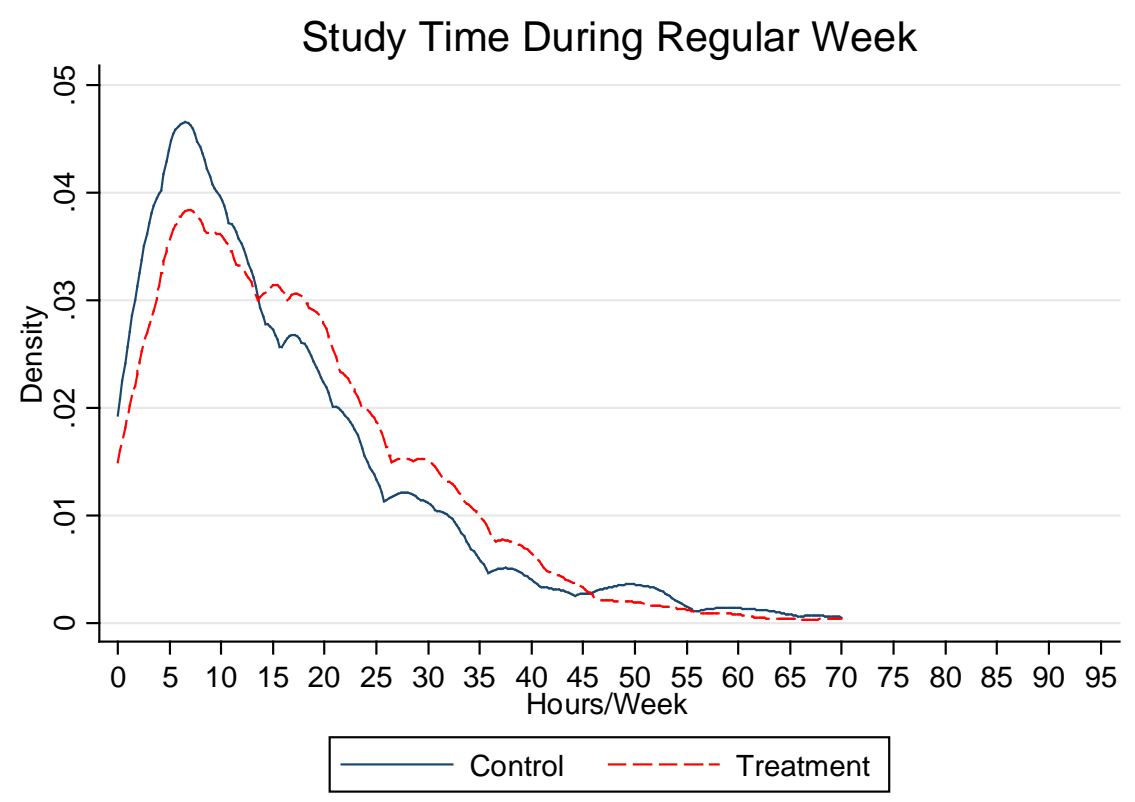

(a): Density of Student Study Time During a Regular Week

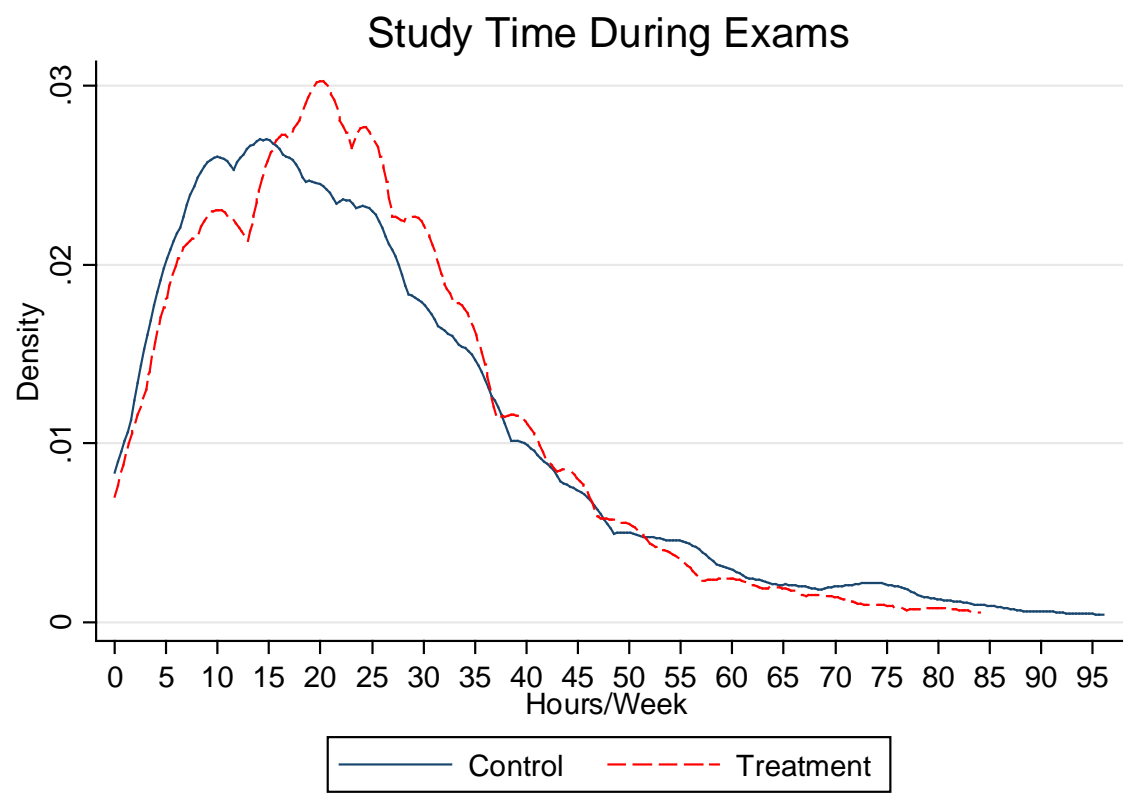

(b): Density of Student Study Time During a Exams

\section{Figure 6: Densities of Study Time}

Notes: Panel (a) presents the densities of student study time during an average regular week without midterms or exams approaching. Panel (b) presents the densities of student study time during a week with midterms or exams approaching. The blue solid line in each panel is the density for the control group; the red dashed line in each panel is the density for the treatment group. The samples in each panel consist of students across both campuses of UofT. 


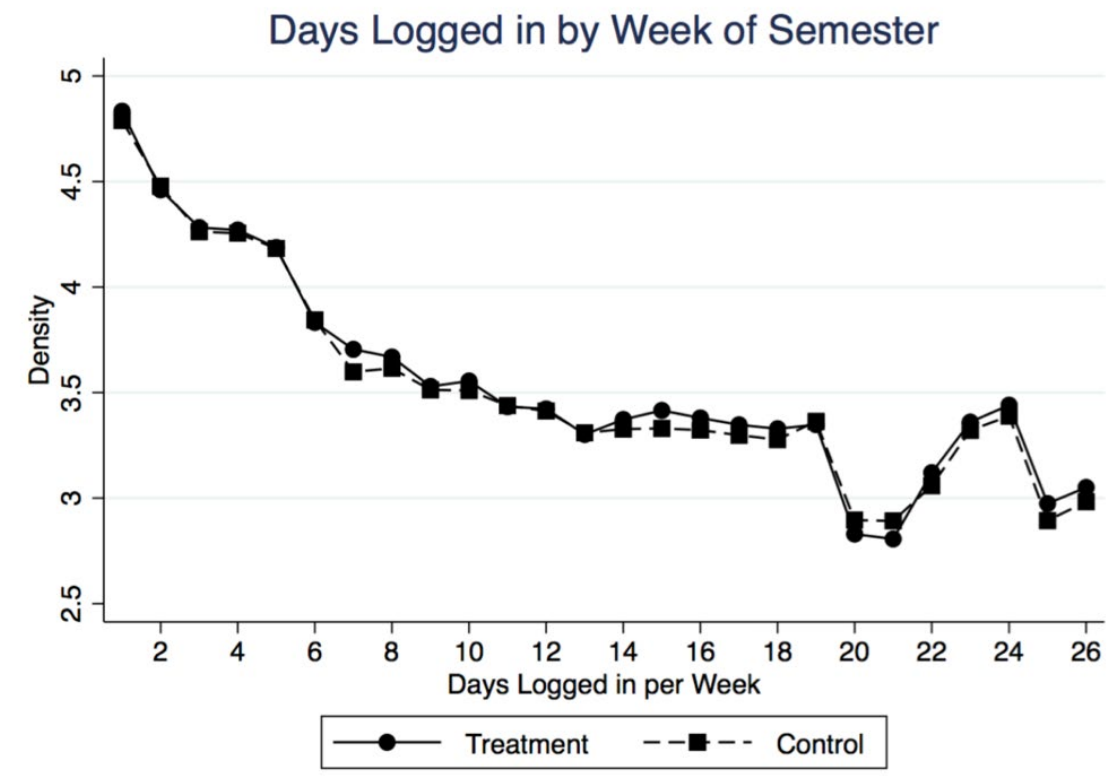

Figure 7: Days Logged in By Week of Semester

Notes: This figure shows the average number of days students log into the WGU website for each week during their first semester. The solid line is for the treatment group and the dashed line is for the control group. The data used is for WGU students in the experimental sample. 